\& Education

Elsevier Editorial System(tm) for Computers

Manuscript Draft

Manuscript Number:

Title: Exploring the Phenomenon of Distance in Children's Interactions with Touchscreen Digital Mathematics Games

Article Type: Research Paper

Keywords: distance; educational technology; mathematics; digital games; touchscreen

Corresponding Author: Dr. Stephen I Tucker, Ph.D.

Corresponding Author's Institution: University of Louisville

First Author: Stephen I Tucker, Ph.D.

Order of Authors: Stephen I Tucker, Ph.D.; Patricia S Moyer-Packenham, Ph. D.

Abstract: This study examines the construct of distance-the degree of difficulty of interacting with something-as part of activity involving children using touchscreen digital games to learn mathematics. Ten fifthgrade children engaged in video-recorded semi-structured task-based interviews in which they used two touchscreen digital mathematics games on a touchscreen tablet and responded to semi-structured follow-up questions. Qualitative data analysis was iterative, featuring analytic memoing and eclectic coding techniques to identify themes related to distance. In advanced coding stages, magnitude coding was used to characterize the degree of distance present. Findings provide evidence of the presence of distance, changes in distance, and interactions between distance types throughout the activity. In particular, both mathematical distance and technological distance were present, changed in various ways, and often influenced each other. Implications include the relevance of distance for designing, implementing, and researching educational technology.

Suggested Reviewers: Silke Ladel Ph.D. Professor, Saarland University

ladel@math.uni-sb.de

Expertise in primary mathematics and learning with technology. Developed ACAT, one of the theories applied in this manuscript.

Seungoh Paek Ph.D.

Associate Professor, Learning Design and Technology, University of Hawaii at Manoa spaekehawaii.edu

Expertise in mathematics education involving multi-modal technology 


\title{
Exploring the Phenomenon of Distance in Children's Interactions with Touchscreen Digital Mathematics Games
}

\author{
Stephen I. Tucker ${ }^{1} \&$ Patricia S. Moyer-Packenham ${ }^{2}$
}

${ }^{1}$ University of Louisville, College of Education and Human Development, 1905 South 1st Street, Louisville, Kentucky, 40292, USA

${ }^{2}$ Utah State University, Emma Eccles Jones College of Education and Human Services, 2605 Old Main Hill, Logan, Utah, 84322, USA

Corresponding Author: Stephen I. Tucker (s.tucker@louisville.edu)

\begin{abstract}
This study examines the construct of distance - the degree of difficulty of interacting with something - as part of activity involving children using touchscreen digital games to learn mathematics. Ten fifth-grade children engaged in video-recorded semi-structured task-based interviews in which they used two touchscreen digital mathematics games on a touchscreen tablet and responded to semi-structured follow-up questions. Qualitative data analysis was iterative, featuring analytic memoing and eclectic coding techniques to identify themes related to distance. In advanced coding stages, magnitude coding was used to characterize the degree of distance present. Findings provide evidence of the presence of distance, changes in distance, and interactions between distance types throughout the activity. In particular, both mathematical distance and technological distance were present, changed in various ways, and often influenced each other. Implications include the relevance of distance for designing, implementing, and researching educational technology.
\end{abstract}

\section{Keywords:}

distance, educational technology, mathematics, digital games, touchscreen

Declaration of interest: none

Funding Sources: This research did not receive any specific grant from funding agencies in the public, commercial, or not-for-profit sectors. 


\section{Exploring the Phenomenon of Distance in Children's Interactions with Touchscreen Digital Mathematics Games}

\section{Introduction}

Educational technology, including mobile devices such as touchscreen tablets and digital games, play important roles in learning and teaching mathematics (e.g., National Council of Teachers of Mathematics, 2000; National Governors Association Center for Best Practices \& Council of Chief State School Officers, 2010). To understand design, implementation, and learning in relation to technology, one must understand constructs that contribute to interacting with technology. A construct that warrants attention is distance, which is the "degree of difficulty in understanding how to act upon [something] and interpret its responses" (Sedig \& Liang, 2006, p. 184). Investigating manifestations of distance as children use touchscreen technology to learn mathematics can therefore inform design, implementation, and research related to educational technology.

\subsection{Using touchscreen technology to learn mathematics}

Research indicates that using touchscreen technology can contribute to mathematical learning. Studies have shown that using certain touchscreen digital games can lead to improvements in outcomes related to mathematics tasks (Holgersson, Barendregt, Rietz, Ottosson, \& Lindström, 2016; Riconscente, 2013; Zhang, Trussell, Gallegos, \& Asam, 2015), yet effects can vary by children's age and the mathematics content (Authors, 2015). Characteristics of the digital games may also influence these effects, including required input modalities and gestures (Dubé \& McEwen, 2015; Segal, Tversky, \& Black, 2014), affordances (Authors, 2016a, 2016b), and overall developmental appropriateness (Larkin, 2015). Many digital games fail to take advantage of the multi-touch capabilities of touchscreen technology (Byers \& Hadley, 2013), but multitouch gestures may offer unique possibilities for learning mathematics (Baccaglini-Frank \& Maracci, 2015; Sinclair \& de Freitas, 2014). Children can learn mathematics as they use digital games individually (Authors, 2016c; Holgersson, Barendregt, Emanuelsson, et al., 2016) or socially (Sinclair, Chorney, \& Rodney, 2015; Sinclair \& Pimm, 2015). Evidence of this learning has been found by comparing pre- and post- assessment performance (Paek, 2012; Riconscente, 2013), examining affordance access (Authors, 2016a, 2016d), and investigating progress along learning trajectories (Authors, 2015b, 2017a), with some reports touching on all three areas (Holgersson, Barendregt, Emanuelsson, et al., 2016).

\subsection{Artifact-Centric Activity Theory}

One useful framework for examining children's experiences with technology such as digital games is Artifact-Centric Activity Theory (ACAT) (Ladel \& Kortenkamp, 2013, 2016). ACAT originates in Activity Theory, in which activity is the interaction between subject (e.g., human) and object (e.g., mathematics) (Leontiev, 1978). Through this activity, humans internalize and externalize their developing understandings of the object. ACAT expands on Activity Theory, accounting for other elements that influence this activity (see Figure 1). The main axis of ACAT involves the activity between the subject (e.g., child) and the object (e.g., mathematics), with the artifact (e.g., touchscreen digital game) as mediator (Ladel \& Kortenkamp, 2013, 2016). This activity includes an exchange consisting of the subject 
internalizing interpretations of the representations of the object presented by the artifact and externalizing these changing internal representations. During this activity, changes in ways of externalizing representations and changes in the externalized representations are evidence of learning. The lower left triangle of ACAT is the involvement of the group (e.g., other children, teacher) in the subject-artifact relationship, including support from teachers and peer participation in internalizing and externalizing representations and constructing meaning. The upper right triangle of ACAT is the influence of the rules (e.g., design considerations from technology and mathematics education) in the artifact-object relationship, including considerations of learning goals and requirements for communicating with the digital game. This study primarily focuses on the main axis, particularly the subject-artifact portion, as in this context the subject can only access the object as it is represented by the artifact.

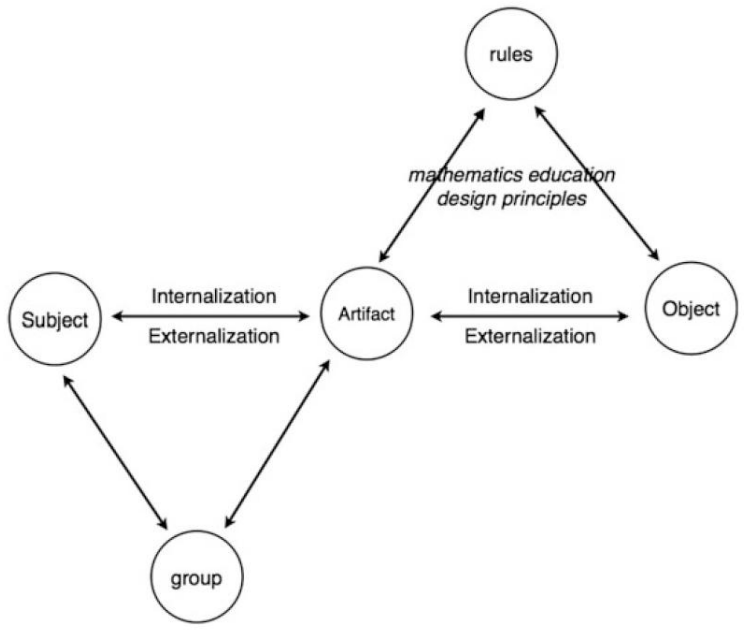

Figure 1. The Artifact-Centric Activity Theory (Ladel \& Kortenkamp, 2016, p. 30)

\subsection{Distance}

Distance is an important construct to consider as children use technology, as it characterizes the difference between what a child does and what the technology requires for productive outcomes. There are multiple types of distance (e.g., Authors, 2016e; Sedig \& Liang, 2006), and maintaining an appropriate amount of distance through purposeful modification is key to maintaining engagement, which promotes learning with technology (Sedig, Klawe, \& Westrom, 2001). This step-wise modification of distance can involve scaffolding, which involves adjusting task characteristics so the tasks remain appropriate for the learners (Wood, Bruner, \& Ross, 1976). This relates to the Zone of Proximal Development (Vygotsky, 1978), as applied to progressive mastery of developmentally appropriate instructional objectives while interacting with technology (Murray \& Arroyo, 2002).

Distance originates in the difference between relevant clusters of attributes (Authors, 2016e), which are characteristics of people or things ("attribute [Def. 5]," 2014). Using a lens of ACAT, we focus on attributes of the subject (e.g., child) and the artifact (e.g., technology). In this context, attributes related to the object (e.g., mathematics) are only evident as represented by subjects and artifacts. There are multiple categories of attributes, which in this theoretical context and application to learning mathematics are attributes of subjects and artifacts. Subjects have mathematical, technological, and personal attributes, whereas artifacts have mathematical, 
technological, and structural attributes (Authors, 2015c, 2016e). Mathematical attributes relate to the object, and include content and representations of mathematics (e.g., number line, hundredths, comparison). Technological attributes relate to the physical exchanges between subject and artifact as part of the activity. Technological attributes of the subject include motor skills (e.g., coordinating two fingers to pinch) and familiarity with gestures required to communicate with the artifact (e.g., pinching is a possible gesture). Technological attributes of the artifact include range of recognition of required gestures (e.g., horizontal pinching is ideal but pinch can be accepted unless completely vertical). Subjects also have personal attributes, which relate to personality as it influences the activity, including goals (e.g., speed over accuracy) and affect (e.g., attitude toward activity). Artifact structural attributes include scaffolding (e.g., hints) and feedback (e.g., animation indicating correct answer). Examples of attributes are apparent throughout educational technology literature, including artifact technological attributes (e.g., direct manipulation via gesture recognition: Segal et al., 2014) and subject mathematical attributes (e.g., components of early number sense: Baccaglini-Frank \& Maracci, 2015).

Clusters of attributes in these categories relevant to a given task form distance. For example, the artifact presents the task: "Use $<,>,=$ to compare 0.5 and 0.09 ," and the subject requires attributes including comparison, decimals, symbolic notation, etc. A high degree of distance is present when relevant attributes do not align (e.g., subject is unfamiliar with comparing decimals, choosing $<$ ). A low degree of distance is present when relevant attributes align (e.g., subject fluent in comparing decimals, choosing >). Previous research implies that when the degree of distance is too high, children may focus solely on technological components of the activity (Rick, 2012) or avoid tasks requiring actions perceived as difficult (Authors, in press). However, during activity, many attributes are modified (Authors, 2017b), as represented by changes in the activity and the externalized representations (e.g., subject improves comparison attribute, increases fluency of task completion; artifact presents task with different mathematical content). Attribute modification can also modify distance (e.g., improve comparison attribute, decrease distance), and externalization of changes in subject attributes provides evidence of learning (Authors, 2015c, 2016e). As this occurs, the modification of artifact attributes can also contribute to the step-wise changes in distance.

\subsection{Current study}

While many studies have explored the effects of using touchscreen digital games to learn mathematics, less research has examined the activity itself and constructs relevant to the activity. Research on distance is under-developed, despite its potential relevance to learning associated with technology-mediated activity. Therefore, this study sought to investigate the phenomenon of distance in children's interactions with touchscreen digital mathematics games. The research questions that guided this study were: During children's activity involving touchscreen digital mathematics games, a) What types of distance are present, b) What changes in distance occur, and c) In what ways do the distance types influence each other?

\section{Method}

This study involved fifth-grade children engaged in activity involving two touchscreen digital mathematics games, generating video data and observation notes for iterative qualitative analyses as part of a larger research project (see Authors, 2015c). This study design aligns with 
ACAT, focusing on distance as it occurred during children's use of touchscreen apps to learn mathematics (i.e., artifact-mediated activity involving subjects and objects). Using video data allowed researchers to repeatedly see the activity in action, supported by field notes taken during the activity. Iterative analysis techniques afforded a focus on distance in many potential forms that could occur during the activity.

\subsection{Participants}

Participants were ten fifth-grade children: 4 female and 6 male, 5 ten years old and 5 eleven years old. Ten participants is considered appropriate for achieving data saturation and identifying key themes without diminishing in-depth qualitative analyses (Guest, Bunce, \& Johnson, 2006; Onwuegbuzie \& Collins, 2007). Recruitment involved distributing fliers to parents of eligible fifth-grade students through local elementary schools. No participants had prior experience with the chosen digital mathematics games.

\subsection{Materials and procedures}

Before conducting the study, the lead author piloted the methods, instruments, digital mathematics games, data collection and data analysis techniques with ten pilot participants (see Authors, 2015c). The pilot digital mathematics games were chosen based on many characteristics, including availability for the iPad, target age of 10-11 years old, and developmentally appropriate content organized by levels. The digital mathematics games selected for this study were the two piloted digital mathematics games played independently for the longest average duration with the most positive student responses. The digital mathematics games may have been updated since data collection occurred.

\subsubsection{Digital Mathematics Games}

The study included two digital mathematics games for the iPad: Motion Math: Zoom and DragonBox Algebra 12+. Motion Math: Zoom involves content such as place value, estimation, comparison, density, and magnitude on the number line, including integers from $-10,000$ to 10,000, and decimals to the thousandths place (see Figure 2). This interactive number line representation is a type of "idealized number line" (Kirby, 2013) that was impossible before digital technology (Carpenter, 2013), here featuring changeable scales and fluid movement for number line navigation (Zhang et al., 2015) that are more faithful to the theoretical number line than a concrete or static pictorial representation could be. Communicating with Motion Math: Zoom involves single- and multi-touch gestures to navigate the number line and popping bubbles to place numbers in the correct spaces. Users swipe or drag the number line left or right to change position on the number line. Changing intervals between visible numbers (e.g., ones, tens, hundreds, etc.) requires zooming in or out by horizontally moving two fingers apart ("spreading") or together ("pinching"), respectively. Many of these gestures are conceptually congruent, in that they align with the mathematics involved, which can be beneficial for learning (Segal et al., 2014). For example, the continuous gesture of swiping conceptually aligns with increasing or decreasing along the horizontal number line, whereas horizontally pinching fingers together zooms out, appearing to bring the numbers closer together (i.e., changing interval scale). Notably, using conceptually congruent gestures to navigate an idealized number line may support learning relevant mathematics content, including density (i.e., numbers within ranges on 
the number line) (Authors, in press). Users can attempt the 24 levels non-sequentially, including skipping some levels, depending on their performance. Users can activate or deactivate the "needle," a timer that pops the bubble to end a level if the user is too slow to complete a task. The default needle setting is inactive. However, upon sufficient completion of Level 6, Motion Math: Zoom offers users the opportunity to try Level 15 with the needle active.

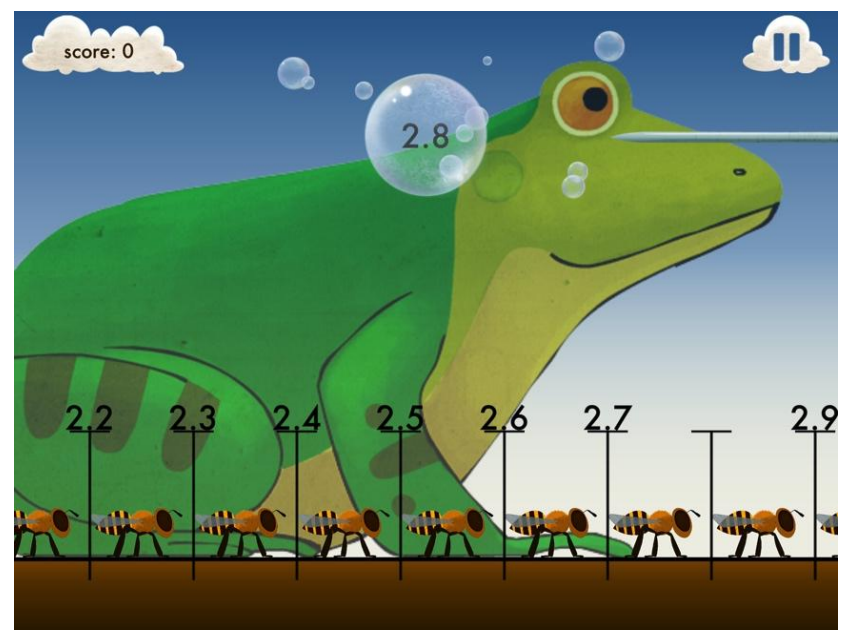

Figure 2. Screenshot of Motion Math: Zoom.

DragonBox Algebra 12+ involves solving expressions and equations using operations, additive and multiplicative thinking, negative and positive values, and fractions. The structure consists of 10 chapters, each of which involves growing a dragon by completing 20 levels. Every level requires the user to solve a unique equation or expression, often requiring several steps combining multiple properties (see Figure 3). DragonBox Algebra 12+ demonstrates new properties or applications of the properties ("new powers") before integrating them into following levels that also include combinations of prior properties. Although the iPad affords multi-touch gestures, communicating with DragonBox Algebra 12+ involves only single-touch gestures to tap or drag tiles. DragonBox Algebra 12+ presents levels sequentially, but users may choose any previously attempted level via the level menu. Within a level, users can undo a move, restart a level, or watch an animation of the solution to the level by selecting menu options. All ten participants reached levels involving additive equality, inverse, and identity properties. 


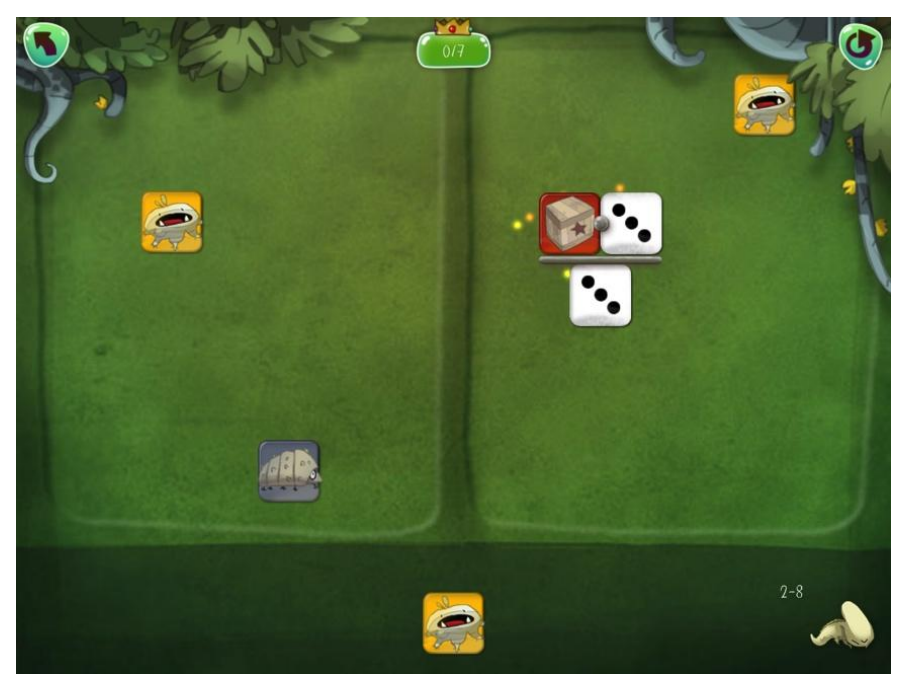

Figure 3. Screenshot of DragonBox Algebra 12+.

\subsubsection{Procedures and Data Collection}

Data collection occurred in an early childhood research center on the campus of a university in the Intermountain West of the United States. Each child participated in one videorecorded individual task-based interview conducted by a researcher, as in other investigations focusing on activity involving children's use of touchscreen digital mathematics games (e.g., Authors, 2015a, 2017c). During the semi-structured task-based interview (cf. Goldin, 2000), the researcher provided problem-solving environments (i.e., digital mathematics games) that presented tasks in an organized manner (i.e., levels), but the researcher did not help participants with task completion. To complement the video recordings focusing on the hands-on space (see Figure 4), the interviewer took observation field notes, providing data from multiple sources to address the research questions (Creswell \& Plano-Clark, 2011).

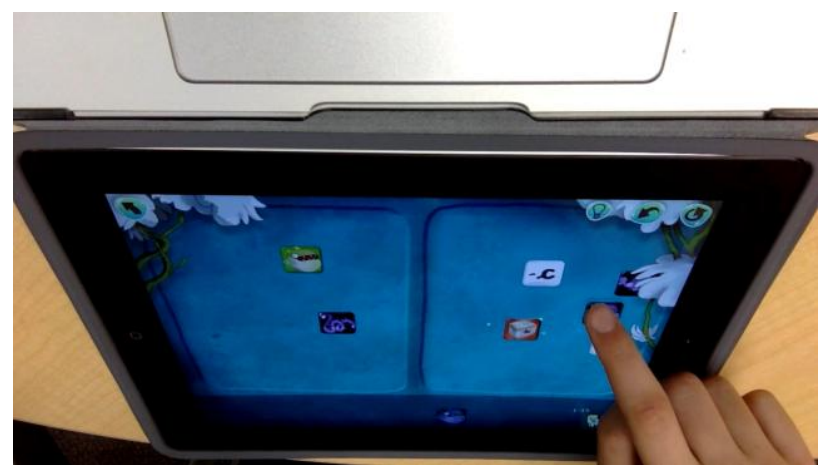

Figure 4. Screenshot from video of a participant using DragonBox Algebra 12+

The semi-structured interview began with an introduction to familiarize the participant with the procedure. The participant then used one digital mathematics game for up to 30 minutes, with the option to stop at any time. After this, the interviewer asked relevant follow-up questions. The process repeated for the second digital mathematics game. Finally, the interviewer asked brief, semi-structured summative questions. All questions were semi-structured to account for participants' responses while focusing on key themes (Rossman \& Rallis, 2003). 


\subsection{Data analysis}

The iterative data analysis process involved eight interrelated stages of analytic memoing, eclectic coding, interpretation, and analysis of the video recordings and observation field notes during and after data collection as part of a larger research project (see Authors, 2015c). Video captures a record of motion and allows flexible choice of grain size to repeatedly examine activity occurring over different time scales (e.g., thirty minutes vs. two seconds) (Derry et al., 2010), making it ideal for studying action. Analytic memoing involves recording information and interpretations relevant to the data and the analysis process in textual form, in this context to accompany visual data, effectively as descriptive and interpretive commentary (Miles, Huberman, \& Saldaña, 2013; Saldaña, 2013). Eclectic coding involves applying an array of initial coding techniques before recoding after interpreting the initial coding (Saldaña, 2013). These techniques allowed for flexible, iterative data analyses to attempt to convey the actions (i.e., activity) and interpretations.

Analysis included development and refinement of codes pertaining to distance (e.g., "mathematical distance") from groups of related memos across multiple coding cycles. These were organized into themes that informed the specific research questions (e.g., "increase in distance" addresses changes in distance). Analyses also involved development of magnitude codes to indicate the degree or intensity of the coded construct (Saldaña, 2013) to represent the degree of each type of distance evident during an attempt to complete a level from beginning to end (e.g., task shown until completion, prompt to restart, or exit). Each overall distance magnitude code was comprised of several contributing magnitude codes (e.g., technological distance when using Motion Math: Zoom influenced by efficiency of swiping and efficiency of zooming). All magnitude codes involved a four-point scale, with 1 representing the greatest degree of distance (i.e., least efficacy, little attribute alignment) and 4 representing the least degree of distance (i.e., greatest efficacy, closely aligned attributes). The component code values were used to determine the overall distance magnitude code value. Each distance magnitude code thus represented an evaluation based on the presence of multiple components. The magnitude codes were used to create summary tables to facilitate comparison and pattern identification, rather than statistical comparison. Analyses also involved grouping levels within the digital mathematics games based on task characteristics (e.g., Motion Math: Zoom Levels 2-6: Integers to 1,000). (See Authors, 2015c for details regarding magnitude coding and level grouping.)

\section{Findings}

The first section presents evidence of the three themes: a) two distance types: mathematical distance and technological distance, b) changes in distance, and c) interactions between distance types. The second section illustrates the themes in extended vignettes.

\subsection{Distance types, changes, and interactions}

\subsubsection{Mathematical distance and technological distance}

Two types of distance emerged from the analyses: mathematical distance and technological distance. All participants encountered varying degrees of mathematical distance and technological distance during the activity. These distance types emerged from differing alignment of mathematical and technological attributes, though structural and personal attributes 
could also influence distance. Examples including excerpts from analytic memos appear in Table 1 .

Table 1

Examples of Mathematical and Technological Distance

\begin{tabular}{|c|c|}
\hline Motion Math: Zoom & DragonBox Algebra 12+ \\
\hline \multicolumn{2}{|l|}{ Mathematical distance: High degree } \\
\hline $\begin{array}{l}\text { [Needle] popped first task }(0.05) \text {; tried } 0.5 \\
\text { placement even after app filled the empty space } \\
\text { (P02 A8 L15N) }\end{array}$ & $\begin{array}{l}\text { Ends up adding all [variables] from outside and } \\
\text { trying to combine across or within for unlike } \\
\text { [variables]. (P03 A13 L1:12) }\end{array}$ \\
\hline \multicolumn{2}{|l|}{ Mathematical distance: Low degree } \\
\hline $\begin{array}{l}\text { [Chooses] ideal intervals and ranges (P10 A4 } \\
\text { L4) }\end{array}$ & $\begin{array}{l}\text { Replicates solution. Audible deep sigh. (P07 A31 } \\
\text { L1:14) }\end{array}$ \\
\hline
\end{tabular}

Technological distance: High degree

Mixed up zoom in/out gestures (P03 A8 L15N) Misses drag/drop again (P03 A6 L1:06)

Technological distance: Low degree

Controlled zooming when close to interval level Watches new power once, correctly replicates (P04 A8 L18) tap. (P06 A28 L2:05)

Note. Alphanumeric sequences in parentheses indicate references to specific memos. $\mathrm{P}$ indicates participant, A indicates the attempt number, $\mathrm{L}$ indicates level or chapter and level. Brackets indicate clarifications. (Authors, 2015c, p. 83)

Mathematical distance was the degree of difficulty of the mathematical aspects of the activity (i.e., how challenging the mathematical content is for the child). For example, to efficiently complete Chapter 1, Level 12 (Level 1:12) in DragonBox Algebra 12+, participants had to apply the additive identity, additive inverse, and additive equality properties in a specific order. Two participants encountered a very low degree of mathematical distance as they correctly applied their knowledge of these properties to complete the level. However, six participants encountered a very high degree of mathematical distance, struggling to determine the correct order in which to apply the properties and restarting the level at least once.

Technological distance was the degree of difficulty of the technological aspects of the activity (i.e., the child must produce input recognizable to the digital mathematics game). For example, most levels of Motion Math: Zoom required using pinching and spreading gestures to change intervals (i.e., zoom) at some point. Four participants always experienced a very low or low degree of technological distance, efficiently performing these and other gestures when required. However, at times, the other six participants encountered a high or very high degree of technological distance as they struggled to coordinate their fingers to efficiently perform the pinching and spreading gestures. 
Structural and personal attributes could also influence distance, such as during activity involving Motion Math: Zoom. Every participant to attempt a level with the activated needle timer (structural attribute) encountered a high degree of mathematical distance as they attempted to quickly complete tasks before time ran out. However, while some participants also faced a high degree of technological distance with the needle timer active, others managed to perform the gestures without difficulty despite the time constraints. Personal attributes also influenced this activity, such as when participants whose goal was to explore the number line were unable to successfully complete the timed tasks.

\subsubsection{Changes in distance}

The degree of mathematical distance and technological distance could change throughout the activity. Every participant encountered changes in mathematical distance and technological distance. Examples including excerpts from analytic memos appear in Table 2.

Table 2

Examples of Changing Distance

\begin{tabular}{|c|c|}
\hline Motion Math: Zoom & DragonBox Algebra 12+ \\
\hline \multicolumn{2}{|l|}{ Mathematical distance: Decreasing } \\
\hline $\begin{array}{l}\text { P05 } \\
\text { - Much L[eft]-R[ight] confusion.... Imprecise, } \\
\text { non-ideal choices... often travels for } \\
\text { extended time with inefficient interval, but } \\
\text { usually in correct direction (A11 L5) } \\
\text { - Chooses some inefficient intervals... to } \\
\text { travel within... [but] accurate completion } \\
\text { (A12 L6) }\end{array}$ & $\begin{array}{l}\text { P09 } \\
\text { - Begins with incorrect unneeded addition } \\
\text { variable.... Eventually places all variables } \\
\text { and attempts some impossible combos. (A11 } \\
\text { L1:11) } \\
\text { - Quickly correct and complete. (A12 L1:11) }\end{array}$ \\
\hline \multicolumn{2}{|l|}{ Mathematical distance: Increasing } \\
\hline $\begin{array}{l}\text { P06 } \\
\text { - Correct/ideal for } 0.05 \ldots . . \text { For } 1.00 \text { to } 1.53 \text {, } \\
\text { chooses appropriate place to zoom in.... } \\
\text { Balance of sufficient accuracy with lots of } \\
\text { speed--and memory of type of upcoming task } \\
\text { for planning. (A17 L15N) } \\
\text { - } 0.10 \text { from tenths }(0.7)-\text {-right first, then } \\
\text { zoomed in at } 0.5 \text { to travel by hundredths. } \\
\text { (A18 L16N) }\end{array}$ & $\begin{array}{l}\text { P04 } \\
\text { - Combo inside, direct combo from outside } \\
\text { [completes simplified solution] (A15 L1:14) } \\
\text { - Direct combo from outside.... [does not } \\
\text { simplify] opposite side (A16 L1:15) }\end{array}$ \\
\hline Technological distance: Decreasing & \\
\hline
\end{tabular}




\begin{tabular}{|c|c|}
\hline Motion Math: Zoom & DragonBox Algebra 12+ \\
\hline $\begin{array}{l}\text { P03 } \\
\text { - Struggled to zoom out [because] of mixing } \\
\text { up zoom in/out gestures. (A13 L15N) } \\
\text { - Zoomed out for } 0.3 \text { with multiple intervals } \\
\text { showing. Zoomed in for } 0.04 \text { at } 0.1-0.2 \ldots \\
\text { [No] in/out mixups. (A14 L15N) }\end{array}$ & $\begin{array}{l}\text { P02 } \\
\text { - Swipe swirls [instead of tap], app did not read } \\
\text { every time (A5 L1:05) } \\
\text { - Now using correct tech input (A12 L1:12) }\end{array}$ \\
\hline Technological distance: Increasing & \\
\hline $\begin{array}{l}\text { P08 } \\
\text { Thumb swipe at corner of screen for } 5,21 \text {, } \\
\text { 12. Scaffolded zoom for } 15 \text {. (A1 L1) } \\
\text { Nearly vertical zoom... slows progress.... } \\
\text { Scaffolded zoom in replication difficulties.... } \\
\text { For } 0.01 \text { from } 1 . X X \text {, travels by hundredths. } \\
\text { Tries to zoom out but fails. (A2 L15) }\end{array}$ & $\begin{array}{l}\text { P10 } \\
\text { - While holding [variable], sees white highlight } \\
\text { on [inverse], drags closer, sees yellow } \\
\text { highlight, combines (A38 L2:13) } \\
\text { - Some gestures misread or placed/executed } \\
\text { poorly (A39 L2:13) }\end{array}$ \\
\hline
\end{tabular}

Note: Alphanumeric sequences in parentheses indicate references to specific memos. $\mathrm{P}$ indicates participant, A indicates the attempt number, L indicates level or chapter and level. Brackets indicate clarifications. (Authors, 2015c, p. 86)

During activity involving DragonBox Algebra 12+, mathematical distance often changed as participants encountered a new power (i.e., application of a mathematical property).

Participant 10 noticed the scaffolding via demonstration and task sequence, stating that, "It starts off easy and then gets harder and it tells you what to do at first and then you do that on your own on the next one." For example, Level 1:16 introduced a version of the additive inverse property wherein the user had to identify a variable from outside the equation space and tap it to create the inverse, then bring it into the equation space (i.e., multiply by -1 and add to both sides of the equation). Most participants encountered a very low degree of mathematical distance on this straightforward task with a demonstration. However, Level 1:17 removed the demonstration scaffolding and mathematical distance increased for nine participants. Levels 1:18-1:20 each involved more complex equations featuring the new property in various combinations with previously encountered properties. While attempting this group of levels, all ten participants encountered a high or very high degree of mathematical distance at least once, and eight participants repeated one or more levels. The most common errors involved adding the external variable without multiplying it by -1 first (i.e., adding 1 instead of -1) and leaving an inelegant solution by not completely simplifying the equation (e.g., $\mathrm{X}=\mathrm{Y}+-\mathrm{Y}+\mathrm{Z}$ ). While some participants demonstrated a somewhat improved application of the mathematical properties and generally decreased mathematical distance during this group of levels, other participants continued to struggle and did not encounter very low mathematical distance again until reaching the next demonstration level.

During activity involving Motion Math: Zoom, technological distance often changed as participants relied on zooming to navigate. Although all ten participants encountered a low or very low degree of distance when zooming was first introduced (Level 1), it was not intended as the most efficient way to complete most tasks until Level 6. Of the seven participants who attempted Levels 1-6 in sequence, only Participant 1 encountered a high or very high degree of distance on a task, yet four encountered a relatively higher degree of technological distance when 
zooming was required than when zooming was not required. Of the seven participants who attempted Level 15 with the needle timer active, only Participant 9 did not encounter an increase in the degree of technological distance. Each of these participants honed their zooming techniques and decreased technological distance to a very low degree by their final attempts on Level 15 (see Figures 5a-5d). Yet even when the degree of technological distance was relatively low, gestures used for zooming did not always take full advantage of the potential for conceptual congruence, often remaining diagonal rather than horizontally aligned with the number line.
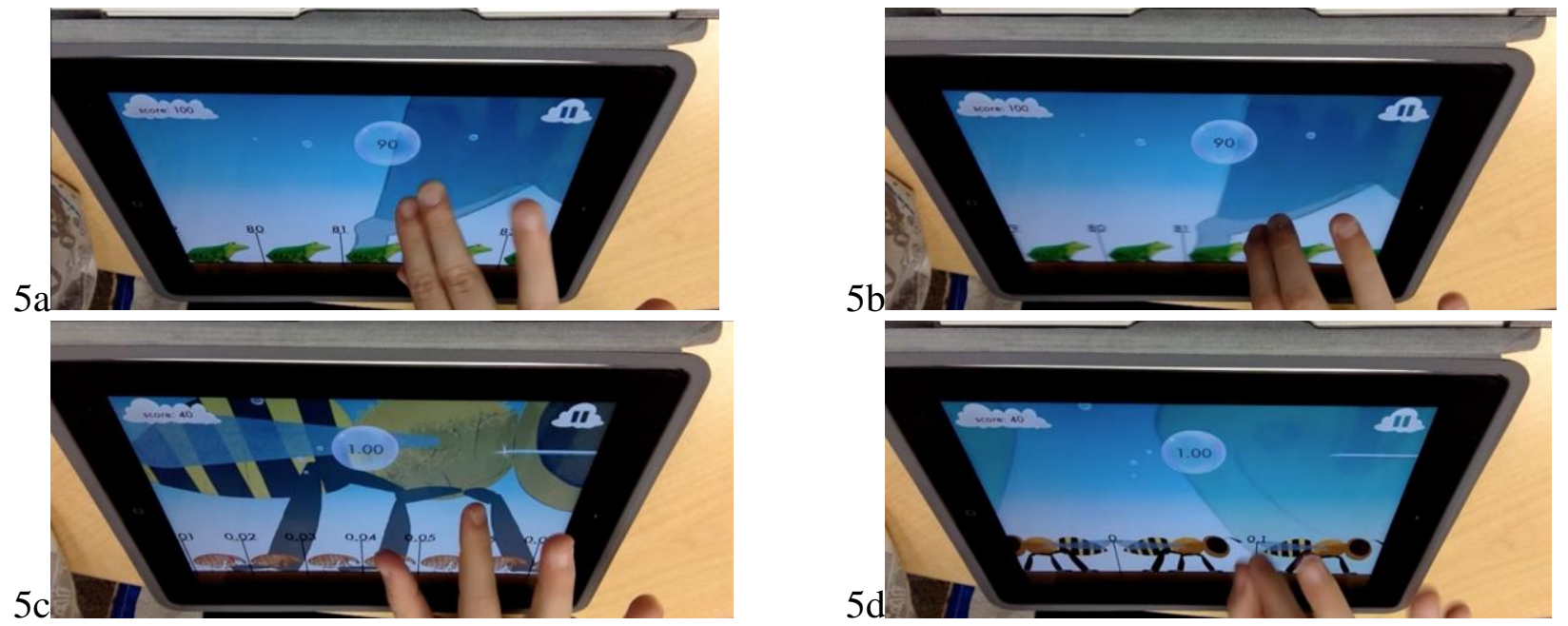

Figures 5a.-5d. Examples of changes in technological distance related to using the pinching gesture to zoom out. 5a-5b: High degree of technological distance: Participant 1 struggles to zoom out using a nearly vertical pinching gesture. $5 \mathrm{c}-5 \mathrm{~d}$ : Decreased degree of technological distance: Participant 1 zooms out using a pinching gesture that is closer to the horizontal orientation of the number line.

\subsubsection{Interplay between distance types}

Participants had to coordinate mathematical and technological elements of the activity, such as determining a range in which to zoom (mathematics) and using swipe and zoom (i.e., pinch and spread) gestures to navigate to that place (technology). Every participant encountered times when distance types influenced each other. Examples including excerpts from analytic memos appear in Table 3.

Table 3

Interplay between Mathematical Distance and Technological Distance

\begin{tabular}{ll}
\hline \multicolumn{1}{c}{ Motion Math: Zoom } & \multicolumn{1}{c}{ DragonBox Algebra 12+ } \\
\hline $\begin{array}{l}\text { P03 } \\
\text { - Gesture is two-hand mostly horizontal and } \\
\text { quick--app struggles to read at times (may } \\
\text { touch too lightly?). Chooses correct interval for } \\
\text { zooming, but zoom becomes diagonal and } \\
\text { [difficult] for app to recognize (A4 L4) }\end{array}$ & $\begin{array}{l}\text { Tries to divide by appropriate [variable] but } \\
\text { misses--ends up then trying to [add] (A35 }\end{array}$ \\
$\begin{array}{l}\text { L2:13) } \\
\text { Reverses zoom in/out gestures and ends up } \\
\text { traveling at inefficient interval (A6 L6) }\end{array}$ & $\begin{array}{l}\text { Tries to use two [variables] at the same time } \\
\text { (multi-touch) (A40 L2:13) }\end{array}$ \\
\hline
\end{tabular}


DragonBox Algebra 12+

P06

- Multiple extra one-dot [coefficients made] when drag/tap input mistakes. Ends up with extra moves. (A32 L2:09)

- Creates extra one-dot [coefficients] while trying to combine variables before clearing [coefficient] (A33 L2:10)

- Accidentally makes one-dot [coefficient] while trying to drag (A36 L2:12)

Note. Alphanumeric sequences in parentheses indicate references to specific memos. P indicates participant, A indicates the attempt number, L indicates level or chapter and level. ZFT indicates Motion Math: Zoom Follow-Up Questions Transcript. Quotation marks indicate direct quotes from participants. Brackets indicate clarifications. (Adapted from Authors, 2015c, p. 104)

Often, technological distance influenced mathematical distance, such as when Participant 3 struggled to use conceptually congruent zooming gestures that Motion Math: Zoom could easily recognize. Some participants implied connections between mathematical distance and technological distance. After using Motion Math: Zoom, Participant 4 reflected that:

Whole numbers was really easy so I changed to decimals. Hundredths was still fairly easy and thousandths.... was a little bit harder because there was more zooming in and sometimes it got a little confusing. Same with negatives cuz like I'm so used to positives where you go forward I was not used to going backward to get to a higher number. As the mathematics content became more challenging, mathematical distance increased. The activity also required more zooming to change intervals, which Participant 4 found confusing, providing evidence of increased technological distance. Furthermore, Participant 4 coordinated the mathematical and technological elements of the activity, adjusting to "going backward" for negative numbers, and varying the extent of swiping, pinching, and spreading gestures to change how fast and how far the number line moved left to right or changed intervals.

Participant 8 also noted a connection between the mathematical and technological elements of the activity, yet at times struggled to decrease technological distance enough to attend to the mathematics and decrease mathematical distance.

Interviewer: How did you decide where to zoom?

Participant 8: If things kinda take me a long time to get in to places... I'd decide I want to go to the frog area [intervals of 1] and I pick an area between 1 and 2 or 3 and 4 then zoom in to the area close enough where the center of the screen was, and it would zoom in really close to where I wanted it to zoom into.

Interviewer: Wow... so was it easy? Hard?

Participant 8: It was easy, but it just wouldn't let me pass the level I was on for some reason. Well it was easy, but it wouldn't give me enough time to do stuff because it was super-hard to get to areas you wanted to go to.

Interviewer: Why was it hard to get to those areas?

Participant 8: Because I picked the decimals in the thousandths place and when trying to find the thousandths place area where I want to go to, I swiped the screen so much it just would be kinda annoying to get to the place where I want to be and pop the bubble. 
Participant 8 characterized the mathematics content as "easy" yet found it "super-hard" to access some of it. Choosing Level 15 with the timer inactive immediately after completing Level 1, Participant 8 often encountered high degrees of mathematical distance and technological distance. Participant 8 struggled both to efficiently perform zoom gestures and to consistently choose appropriate ranges to zoom. Despite intentionally choosing where to change intervals when tasks involved finding tenths from whole numbers (e.g., "between 1 and 2" for 1.5), Participant 8 was less precise for tasks involving hundredths, leading to time-consuming swiping to place the target number. This was due both to a less-developed knowledge of decimals to hundredths - which Participant 8 referred to as "thousandths"- and the use of inefficient zooming gestures that sometimes moved the number line to an unintended location. For example, to find 1.59 with intervals of one and the screen centered on 1.00, Participant 8 inefficiently zoomed in closer to 0 , ending up with intervals of one hundredth and the screen centered on 0.00 . Participant 8 then swiped until the number line reached 1.59 rather than choosing a more efficient path (e.g., zoom to tenths between 1 and 2, zoom to hundredths between 1.50 and 1.60). This demonstrated a high degree of mathematical distance stemming from Participant 8's uncertainty of density to hundredths on the number line, even though Participant 8 swiped in the correct direction (i.e., accurately compared numbers written out to hundredths). This was coupled with a relatively high degree of technological distance as Participant 8 struggled to zoom efficiently. Thus, when tasks involved hundredths, Participant 8 relied on conceptually congruent but inefficient swiping to horizontally increase or decrease magnitude on the number line, inconsistently accessing the conceptually congruent, efficient zooming needed to fully explore intervals and density.

Activity involving DragonBox Algebra 12+ also revealed interplay between mathematical distance and technological distance. For example, Participant 2 at times struggled to use a gesture DragonBox Algebra 12+ could recognize, leading to misplaced variables. The high degree of technological distance led to a higher degree of mathematical distance. Similarly, when required to tap a tile to apply the multiplicative identity property many participants, including Participant 6, instead attempted to drag the tile, often resulting in duplicating the tile instead of removing it (i.e., multiplying by 1 instead of dividing by 1) (see Figures 6a-6c).

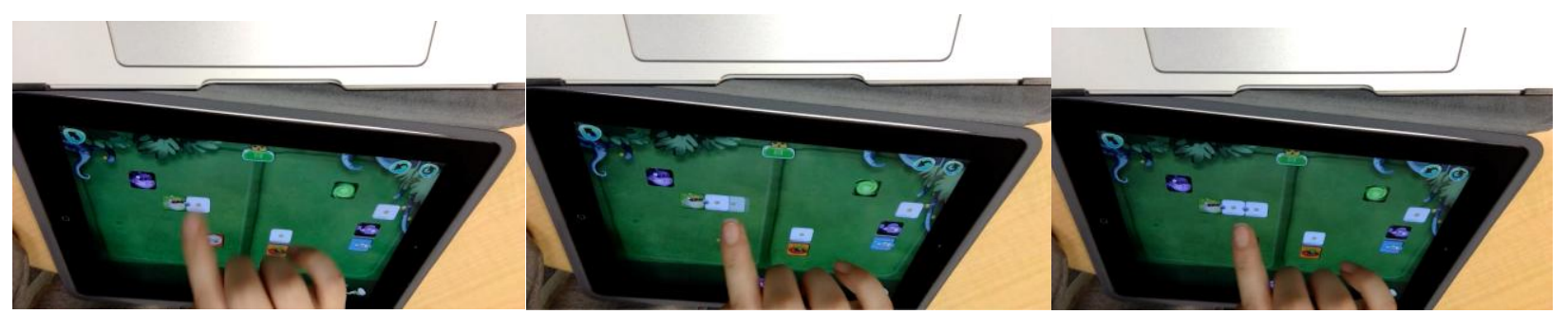

Figures $6 a-6 c$. Technological distance influencing mathematical distance while attempting to apply the multiplicative identity property. 6a: Participant 2 is about to touch the white one-dot tile. 6b: Participant 2 has touched the one-dot tile using a mix of a tap gesture (here representing "divide by 1") and a drag gesture (here representing "multiply by 1"). 6c: DragonBox Algebra $12+$ generates another one-dot tile, having interpreted the gesture as a drag.

\subsection{Vignettes}

The following vignettes exemplify themes related to distance evident during the activity. The first vignette involves the degree of mathematical distance changing while the degree of 
technological distance remains consistent. The second vignette involves the degrees of mathematical distance and technological distance influencing each other as they both change.

\subsubsection{DragonBox Algebra 12+ Vignette}

Participant 7's activity involving DragonBox Algebra 12+ illustrated changes in the degree of mathematical distance while the degree of technological distance remained constant (see Table 4). Throughout all 43 attempts, Participant 7 maintained a very low degree of technological distance, swiping, tapping, and dragging fluently enough for the DragonBox Algebra 12+ to recognize. However, Participant 7's mathematical distance varied throughout the activity. Participant 7 completed the first two levels with minimal mathematical distance, effectively applying the additive identity property. However, mathematical distance increased at times during the second group of levels, which involved integrating the additive inverse property using tiles already present in the equation without moving the variable from one side of the equation to the other. During this time, Participant 7 sometimes struggled to apply the correct properties in order, such as on Attempt 7. However, Participant 7 repeatedly used the "undo" option to retrace the steps taken until successfully completing the task.

Table 4.

Degree of Mathematical and Technological Distance during Participant 7's Activity Involving DragonBox Algebra 12+ (Excerpts)

\begin{tabular}{crrrr}
\multicolumn{4}{c}{ Level } & \multicolumn{3}{c}{ Distance } \\
Attempt & Group & Number & Mathematical & Technological \\
\hline 1 & 1 & $1: 01$ & 4 & 4 \\
2 & 1 & $1: 02$ & 4 & 4 \\
3 & 2 & $1: 03$ & 4 & 4 \\
4 & 2 & $1: 04$ & 4 & 4 \\
5 & 2 & $1: 05$ & 3 & 4 \\
6 & 2 & $1: 06$ & 4 & 4 \\
7 & 2 & $1: 07$ & 2 & 4 \\
8 & 2 & $1: 08$ & 4 & 4 \\
9 & 3 & $1: 09$ & 4 & 4 \\
10 & 3 & $1: 10$ & 4 & 4 \\
11 & 3 & $1: 11$ & 4 & 4 \\
12 & 3 & $1: 12$ & 1 & 4 \\
13 & 3 & $1: 12$ & 3 & 4 \\
14 & 3 & $1: 13$ & 4 & 4 \\
15 & 3 & $1: 14$ & 1 & 4 \\
29 & 3 & $1: 14$ & 1 & 4 \\
30 & 3 & $1: 14$ & 1 & 4 \\
31 & 3 & $1: 14$ & 4 & 4 \\
32 & 3 & $1: 15$ & 1 & 4 \\
33 & 3 & $1: 15$ & 2 & 4 \\
34 & 4 & $1: 16$ & & 4
\end{tabular}


1:17

36

42

43
1:18

1:18

1:18
2

4

4

4

4

Note. Attempt denotes position in overall sequence of attempts to complete any level of DragonBox Algebra 12+. Level: Group denotes the set of related levels. Level: Number denotes the Chapter and Level within the chapter attempted. Distance: Mathematical denotes degree of mathematical distance. Distance: Technological denotes degree of technological distance. Full table including all attempts appears in Appendix A, Table A1.

Soon, Participant 7 progressed to the third group of levels (Attempts \#9-33), which involved integrating the additive equality property with bringing variables from outside the equation space. Participant 7 successfully completed the scaffolded and simplest levels in this group with minimal mathematical distance before struggling to complete Level 1:12. However, Attempts 15-30 all involved a high degree of mathematical distance on Level 1:14, where Participant 7 struggled to effectively apply the mathematical properties necessary to complete the task, repeatedly adding multiple unnecessary variables, becoming confused, and restarting the level (see Figures 7a-7c and Video 1). Participant 7 watched the solution multiple times before finally decreasing the degree of mathematical distance enough to complete the level on Attempt 31. Next, Participant 7 encountered very high degree of mathematical distance on the final level in the third group, struggling to apply the properties in the correct order before restarting. On the next attempt, Participant 7 decreased mathematical distance enough to complete the level and group, repeatedly using undo to backtrack and correctly apply the properties to create a correct, albeit inelegant solution (e.g., $\mathrm{X}=\mathrm{Y}+-\mathrm{Y}+\mathrm{Z}$ ). The fourth group of levels involved integrating the additive inverse property bringing in variables from outside the equation space. Participant 7 completed the introductory scaffolded level with a low degree of mathematical distance, but then encountered high degrees of mathematical distance, repeatedly struggling to apply the correct properties. After multiple failed attempts to complete Level 1:18, Participant 7 watched the solution to identify the correct answer and replicated it to complete the level, decreasing mathematical distance to very low as the time allotted to use DragonBox Algebra 12+ ended.

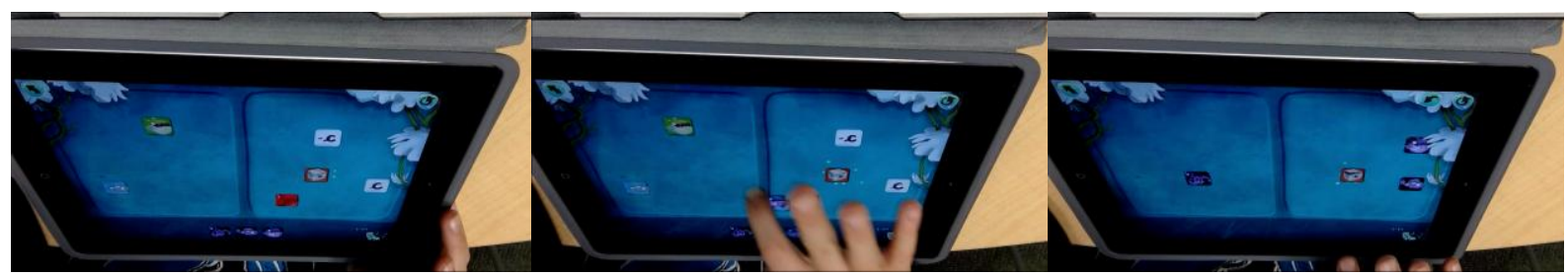

Figures $7 a .-7 c$. Screenshots from an early attempt on Level 1:14 by Participant 7. 7a: Task presented for Level 1:14. 7b: Participant 7 begins by adding an unnecessary variable. 7c: Participant 7 has used all potential variables, including those that are unnecessary, leading to no possible way to solve without undoing steps or restarting. Video 1 includes the full attempt from which the screenshots were taken.

\subsubsection{Motion Math: Zoom Vignette}

Participant 10's activity involving Motion Math: Zoom illustrated changes in mathematical distance and technological distance, as well as instances where distance types influenced each other (see Table 5). Participant 10 encountered low degrees of mathematical 
distance and technological distance during the scaffolded tutorial level (Level 1), effectively completing the mathematical and technological aspects of the tasks. Participant 10 began the second group of levels, featuring positive integers in ranges from 0-40 to 0-1,000 and rarely requiring changing intervals, with a low degree of mathematical distance and technological distance. However, the degree of mathematical distance increased slightly on Attempt 5 (Level 5: positive integers 0-1,000) as Participant 10 inconsistently chose efficient navigation intervals (e.g., exclusively navigating by ones from 415 to find 878 ) and ranges (e.g., zooming from tens to ones at 0-10 to find 53). Next, Participant 10 began the third group of levels, which involved positive integers to 10,000 and often required changing intervals. Participant 10 completed Attempt 6 (Level 6: positive integers, 0-10,000) with similar degrees of mathematical distance and technological distance to the previous attempt, zooming and swiping effectively but at times choosing inefficient navigation intervals and ranges.

Table 5.

Degree of Mathematical and Technological Distance during Participant 10 's Activity Involving Motion Math: Zoom (Excerpts)

\begin{tabular}{rrrrrr}
\multicolumn{5}{c}{ Level } & \multicolumn{3}{c}{ Distance } \\
Attempt & Group & Number & Needle & Mathematical & Technological \\
\hline 1 & 1 & 1 & 0 & 4 & 4 \\
2 & 2 & 2 & 0 & 4 & 4 \\
3 & 2 & 3 & 0 & 4 & 4 \\
4 & 2 & 4 & 0 & 4 & 4 \\
5 & 2 & 5 & 0 & 3 & 4 \\
6 & 3 & 6 & 0 & 3 & 4 \\
7 & 6 & 15 & 1 & 1 & 3 \\
8 & 6 & 15 & 1 & 1 & 4 \\
9 & 6 & 15 & 1 & 1 & 3 \\
10 & 6 & 15 & 1 & 2 & 3 \\
26 & 6 & 15 & 1 & 2 & 4 \\
27 & 6 & 15 & 1 & 2 & 4 \\
28 & 6 & 15 & 1 & 2 & 3 \\
29 & 6 & 15 & 1 & 2 & 4 \\
30 & 6 & 15 & 1 & 3 & 4 \\
31 & 6 & 15 & 1 & 4 & 4 \\
32 & 6 & 16 & 1 & 1 & 4 \\
33 & 6 & 16 & 1 & 1 & 4 \\
43 & 6 & 16 & 1 & 1 & 4 \\
44 & 6 & 16 & 1 & 2 & 4 \\
\hline
\end{tabular}

Note. Attempt denotes position in overall sequence of attempts to complete any level of the Motion Math: Zoom. Level: Group denotes the set of related levels. Level: Number denotes the Level attempted. Needle denotes timer function; 0 is inactive, 1 is active. Distance: Mathematical 
denotes degree of mathematical distance. Distance: Technological denotes degree of technological distance. Full table including all attempts appears in Appendix A, Table A2.

Participant 10 then accepted a prompt to skip levels, moving to the beginning of the sixth group of levels (decimals to hundredths), Level 15 (range of 0-2), with the needle timer active. The degree of mathematical distance and technological distance immediately increased as Participant 10 repeatedly struggled to effectively perform the mathematical and technological aspects of the tasks within the time constraints. In particular, Participant 10 struggled to differentiate between tenths and hundredths (e.g., 0.05 vs. 0.5) and determine efficient navigation intervals (e.g., traveling by hundredths from 0.90 to 0.02) (see Figure 8 and Video 2). Attempts 7-31 all occurred on Level 15. Participant 10 often encountered a low degree of technological distance and a high degree of mathematical distance, gradually decreasing the degree of each over time. This involved honing zooming gestures, making them consistently fluid and conceptually congruent (e.g., horizontally aligned) enough to eventually decrease technological distance to very low. However, many attempts were relatively brief, with the timer function ending the level due to unsuccessful completion of a task, usually because Participant 10 continued to struggle to determine efficient navigation intervals. Nevertheless, Participant 10 appeared to have decreased technological distance enough to focus on the mathematics. By Attempt 31, Participant 10 had become sufficiently adept at choosing efficient navigation intervals (i.e., improved relevant mathematical attributes) on these tasks to decrease mathematical distance to very low on Attempt 31, completing Level 15 (Figure 9 and Supplemental Video 3). For Attempt 32, Participant 10 advanced to Level 16, which expanded the range to $0-10$. The degree of mathematical distance increased to very high as Participant 10 again struggled with the same mathematics in the expanded range. However, Participant 10 maintained a very low degree of technological distance, having become adept at swiping and zooming. After 13 unsuccessful yet relatively brief attempts to complete Level 16, Participant 10's time with Motion Math: Zoom ended with little further change in the degree of either distance. Even so, when asked about interacting with Motion Math: Zoom, Participant 10 stated, "the harder it gets the more you want to find it."

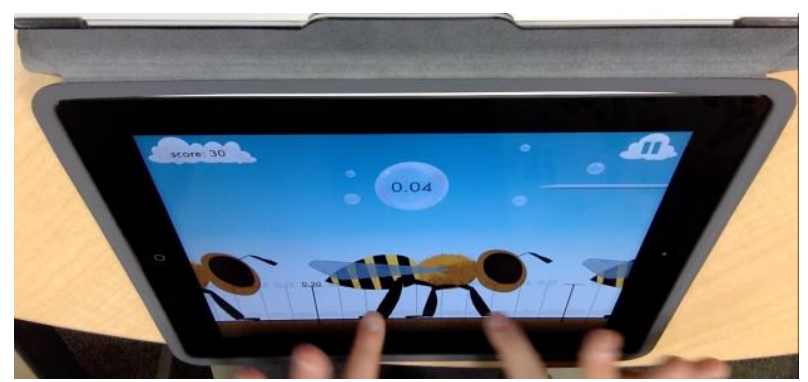

Figure 8. Response to prompt on Level 15 contributing to characterization as low degree of technological distance and high degree of mathematical distance for the attempt: zooming in using conceptually congruent horizontal zoom gesture, but at mathematically inefficient location (i.e., mistaking 0.4 for 0.04 and traveling by hundredths from 0.40 to 0.04 ). Video 2 shows this in action, including two zooming gestures, of which Figure 8 is the second, more conceptually congruent version. 


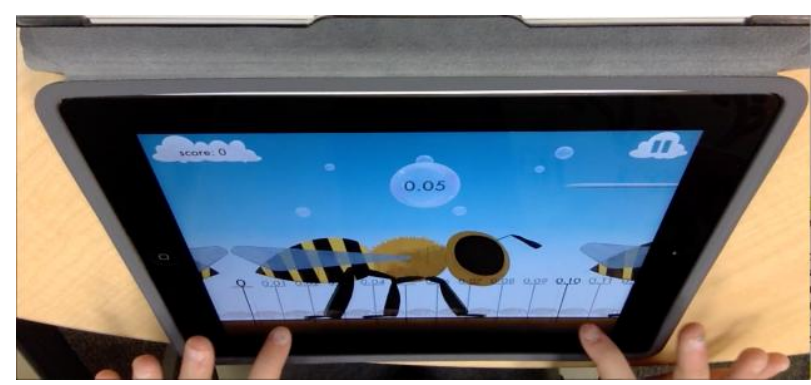

Figure 9. Response to prompt on Level 15 contributing to characterization as very low degree of mathematical distance and very low degree of technological distance for the attempt: fluently zooming in using conceptually congruent horizontal zoom gesture at mathematically efficient location (i.e., 0-0.10 to find 0.05). Video 3 shows this in action.

\section{Discussion}

The goal of this study was to investigate the construct of distance as it manifested during children's activity involving touchscreen technology to learn mathematics. Findings indicated the presence of mathematical and technological distance, that the degree of each distance could change throughout the activity, and that mathematical and technological distance could influence each other. These findings fit within Artifact-Centric Activity Theory (ACAT), link to empirical research, and have implications for those who design, implement, and research educational technology.

\subsection{Addressing the Research Questions}

Expanding on research identifying distance types relative to interactions with educational technology (Authors, 2016e, Sedig \& Liang, 2006), these findings provide evidence of mathematical and technological distance, placing them in the context of ACAT. In ACAT, activity involves interaction between subject and object, mediated by an artifact (Ladel \& Kortenkamp, 2016). In this study, the touchscreen digital mathematics game (artifact) represented the mathematics (object) while allowing the children (subjects) to engage in interactive activity involving the mathematics. Findings indicated that one can apply the construct of mathematical distance to examine differences between the subject's representation of the mathematics in relation to the artifact's representation of the mathematics. Furthermore, one can apply the construct of technological distance to examine differences between the subject's methods of interacting with the technology in relation to the artifact's requirements for interactions, regardless of whether the required input was single-touch or multi-touch. In each case, the distance is based on the differences in relevant attributes (e.g., additive identity property: subject's understanding vs. artifact's representation).

Findings also indicated that distance can change during activity. As attributes changed, distance could also change. For example, participants honed zooming gestures during interactions with Motion Math: Zoom, decreasing technological distance. Changes in mathematical distance were also evident. Most participants began to explore a new mathematical property in DragonBox Algebra 12+ with a low degree of mathematical distance, as the digital mathematics game provided simple tasks and explicit scaffolding to guide completion.

DragonBox Algebra 12+ used a step-wise approach to changing attributes, removing scaffolds, presenting multi-step tasks, and incorporating other mathematical properties. This frequently led to increases in mathematical distance. Participants usually responded by attempting to modify their attributes to decrease mathematical distance enough to complete the tasks. Often, this 
involved attempting to experiment with and apply the properties, but sometimes this occurred through watching and attempting to duplicate the solution. As seen with Participant 7, this led to an array of results, ranging from prompt attribute modification, a decrease in distance, and task completion, to persistent repetition of the same task while struggling to modify attributes and decrease distance (see also Authors, 2017b). For some participants, including Participant 7, it was unclear to what degree they learned some of the mathematical properties, as they repeatedly struggled with the same properties, completing inelegant solutions or accessing the solution scaffolding. Previous research suggests that designing intentional changes in artifact attributes such as scaffolding can modify distance in ways that support student learning (Murray \& Arroyo, 2002; Sedig et al., 2001). However, the struggles participants encountered during the activity indicate that even well-intentioned and well-designed changes in attributes and distance may not always lead to expected outcomes.

Furthermore, findings indicated that distance types influenced each other throughout the activity. When present, a consistently high degree of technological distance may have contributed to a high degree of mathematical distance, potentially hindering exploration of the mathematics. Activity involving Motion Math: Zoom provided various examples. Participant 4 implied links between the actions and the mathematics involved in navigating the idealized number line, with variations in difficulty depending artifact attributes relative to subject attributes. Over time, Participant 10 honed relevant gestures (i.e., subject technological attributes), decreasing technological distance enough to focus on the mathematics involved in the activity. Yet Participant 8's overreliance on one gesture and the associated mathematics is evidence that even when conceptually congruent gestures are involved, children may not effectively access them. Although conceptually congruent gestures can support mathematical learning (Segal et al., 2014) and have great potential when part of activity involving multi-touch technology (Baccaglini-Frank \& Maracci, 2015; Sinclair \& de Freitas, 2014), as in other research (e.g., Authors, in press; Rick, 2012), participants who repeatedly struggled to effectively perform certain gestures had limited access to some relevant aspects of the mathematics. However, most participants in this study decreased technological distance enough to attend to the mathematics, including via conceptually congruent gestures where applicable.

The relationship between mathematical distance and technological distance influenced the activity. When there was a low degree of technological distance, participants also had more opportunity to access the mathematics and potentially decrease mathematical distance. However, when there was a high degree of technological distance, it was often more difficult to access the mathematics. Even when there was a low degree of mathematical distance, a high degree of technological distance meant that participants may not have been fully able to put into effect the mathematics they knew. This inextricable relationship between mathematical distance and technological distance shows the significant role that distance plays in digital games and points to the importance of intentional design that provides multiple means of developmentally appropriate access to the mathematics for users. On the other hand, a relatively high degree of distance contributed to the desire to continue the activity, as evidenced by Participant 10's comments about being more motivated when faced with a challenge. Maintaining an appropriate degree of distance is important for learning (Sedig et al., 2001), but "appropriate" does not necessarily equate to "minimal".

\subsection{Practical Implications and Recommendations}


Taken together, the findings related to distance have implications for those who design, implement, and research educational technology. Distance is based on relevant clusters of subject and artifact attributes (Authors, 2016e), so awareness of this construct may support characterization of what is involved in activity and relationships among these elements, such as what determines the difficulty involved in the activity and how that difficulty changes during the activity. Given that using educational technology, such as touchscreen digital mathematics games, can affect learning outcomes, often positively (e.g., Authors, 2015a; Holgersson, Barendregt, Emanuelsson, et al., 2016; Riconscente, 2013), distance may be useful for examining what contributes to these effects. Although many designers account for current research while developing educational technology, the teacher's role remains important. Most current educational technology offers limited responsiveness and distance modification, following preset task sequences, choosing tasks from a programmed database, or requiring external task creation. In this study, the interviewer avoided offering guidance to participants during the activity. However, teachers and peers (i.e., "group" in ACAT) might influence distance in a classroom setting, such as by suggesting a change in tasks, demonstrating a gesture, or discussing the activity. Future applications of distance might include designing more responsive educational technology and informing teacher support of student learning. To build understandings of activity involving educational technology, future investigations might explore how much of what kinds of distance are appropriate in which contexts and for what purposes, as relationships among types of distance, and links with outcomes. This qualitative investigation featured a fine-grained focus, so research involving characteristics such as integration of teachers and peers, more participants, a longer duration, other touchscreen digital mathematics games, and quantitative data would also complement this study.

\section{Conclusion}

This study provided evidence of distance, changes in distance, and interplay among distance types in the context of children's activity involving touchscreen digital games to learn mathematics. Distance fits within ACAT, and like ACAT, is useful for examining activity involving various subjects, artifacts, and objects. Therefore, distance may be a relevant construct for those who design, implement, and research educational technology, as well as those who study artifact-mediated activity in other contexts. 


\section{References}

Authors, 2015a.

Authors, 2015b.

Authors, 2015c.

Authors, 2016a.

Authors, 2016b.

Authors, 2016c.

Authors, 2016d.

Authors, 2016e.

Authors, 2017a.

Authors, 2017b.

Authors, 2017c.

Authors, in press.

attribute [Def. 5]. (2014). OED Online. Oxford University Press. Retrieved from http://www.oed.com/view/Entry/12931

Baccaglini-Frank, A., \& Maracci, M. (2015). Multi-touch technology and preschoolers' development of number-sense. Digital Experiences in Mathematics Education, 1(1), 727. https://doi.org/10.1007/s40751-015-0002-4

Byers, P., \& Hadley, J. (2013). Traditional and novel modes of activity in touch screen math apps. In J. P. Hourcade, N. Sawhney, \& E. Reardon (Eds.), Proceedings of the 12th International Conference on Interaction Design and Children. New York, NY: ACM.

Carpenter, K. K. (2013). Strategy instruction in early childhood math software: Detecting and teaching single-digit addition strategies (Doctoral Dissertation). Columbia University. Retrieved from http://academiccommons.columbia.edu/catalog/ac:160522

Creswell, J. W., \& Plano-Clark, V. L. (2011). Designing and conducting mixed methods research (2nd ed.). Thousand Oaks, CA: SAGE.

Derry, S. J., Pea, R. D., Barron, B., Engle, R. A., Erickson, F., Goldman, R., ... Sherin, B. L. (2010). Conducting video research in the learning sciences: Guidance on selection, 
analysis, technology, and ethics. Journal of the Learning Sciences, 19(1), 3-53. https://doi.org/10.1080/10508400903452884

Dubé, A. K., \& McEwen, R. N. (2015). Do gestures matter? The implications of using touchscreen devices in mathematics instruction. Learning and Instruction, 40, 89-98. https://doi.org/10.1016/j.learninstruc.2015.09.002

Goldin, G. A. (2000). A scientific perspective on structured, task-based interviews in mathematics education research. In A. E. Kelly \& R. Lesh (Eds.), Handbook of research design in mathematics and science education (pp. 517-545). Mahwah, NJ: Lawrence Erlbaum Associates, Inc.

Guest, G., Bunce, A., \& Johnson, L. (2006). How many interviews are enough? An experiment with data saturation and variability. Field Methods, 18(1), 59-82. https://doi.org/10.1177/1525822X05279903

Holgersson, I., Barendregt, W., Emanuelsson, J., Ottosson, T., Rietz, E., \& Lindström, B. (2016). Fingu-A game to support children's development of arithmetic competence: Theory, design and empirical research. In P. S. Moyer-Packenham (Ed.), International Perspectives on Teaching and Learning Mathematics with Virtual Manipulatives (pp. 123-145). Springer International Publishing. https://doi.org/10.1007/978-3-319-327181_6

Holgersson, I., Barendregt, W., Rietz, E., Ottosson, T., \& Lindström, B. (2016). Can children enhance their arithmetic competence by playing a specially designed computer game? Cursiv, 18, 177-188.

Kirby, K. D. de. (2013). The development of an idealized number line: Differentiating physical inscription from mathematical object. Presented at the American Educational Research Association, San Francisco, CA.

Ladel, S., \& Kortenkamp, U. (2013). An activity-theoretic approach to multi-touch tools in early maths learning. The International Journal for Technology in Mathematics Education, 20(1).

Ladel, S., \& Kortenkamp, U. (2016). Artifact-Centric Activity Theory-A framework for the analysis of the design and use of virtual manipulatives. In P. S. Moyer-Packenham (Ed.), International Perspectives on Teaching and Learning Mathematics with Virtual Manipulatives (pp. 25-40). Springer International Publishing. https://doi.org/10.1007/978-3-319-32718-1_2

Larkin, K. (2015). “An app! An app! My kingdom for an app”: An 18-month quest to determine whether apps support mathematical knowledge building. In T. Lowrie \& R. J. Zevenbergen (Eds.), Digital Games and Mathematics Learning (pp. 251-276). Springer Netherlands. https://doi.org/10.1007/978-94-017-9517-3_13 
Leontiev, A. N. (1978). Activity, consciousness and personality. Englewood Hills: Prentice Hall.

Miles, M. B., Huberman, A. M., \& Saldaña, J. (2013). Qualitative data analysis: A methods sourcebook (3rd ed.). Thousand Oaks, CA: SAGE.

Murray, T., \& Arroyo, I. (2002). Toward measuring and maintaining the Zone of Proximal Development in adaptive instructional systems. In S. A. Cerri, G. Gouardères, \& F. Paraguaçu (Eds.), Intelligent Tutoring Systems (pp. 749-758). Springer Berlin Heidelberg. Retrieved from http://link.springer.com/chapter/10.1007/3-540-47987-2_75

National Council of Teachers of Mathematics. (2000). Principles and standards for school mathematics. Reston, VA: Author. Retrieved from http://www.nctm.org/standards/content.aspx?id=26792

National Governors Association Center for Best Practices, \& Council of Chief State School Officers. (2010). Common Core State Standards for Mathematics. Washington, DC: National Governors Association Center for Best Practices, Council of Chief State School Officers. Retrieved from http://www.corestandards.org/assets/CCSSI_Math\%20Standards.pdf

Onwuegbuzie, A. J., \& Collins, K. M. T. (2007). A typology of mixed methods sampling designs in social science research. Qualitative Report, 12(2), 281-316.

Paek, S. (2012). The impact of multimodal virtual manipulatives on young children's mathematics learning (Doctoral dissertation). Retrieved from ProQuest Dissertations \& Theses Full Text. (UMI No. 3554708)

Rick, J. (2012). Proportion: a tablet app for collaborative learning. In Proceedings of the 11th International Conference on Interaction Design and Children (pp. 316-319). New York, NY, USA: ACM. https://doi.org/10.1145/2307096.2307155

Riconscente, M. M. (2013). Results from a controlled study of the iPad fractions game Motion Math. Games and Culture, 8(4), 186-214. https://doi.org/10.1177/1555412013496894

Rossman, G. B., \& Rallis, S. F. (2003). Learning in the field: An introduction to qualitative research. SAGE.

Saldaña, J. (2013). The coding manual for qualitative researchers (Second Edition). Thousand Oaks, CA: SAGE.

Sedig, K., Klawe, M., \& Westrom, M. (2001). Role of interface manipulation style and scaffolding on cognition and concept learning in learnware. ACM Transactions Computer-Human Interactions, 8(1), 34-59. https://doi.org/10.1145/371127.371159

Sedig, K., \& Liang, H.-N. (2006). Interactivity of visual mathematical representations: Factors affecting learning and cognitive processes. Journal of Interactive Learning Research, 
17(2), 179-212.

Segal, A., Tversky, B., \& Black, J. (2014). Conceptually congruent actions can promote thought. Journal of Applied Research in Memory and Cognition, 4(3), 124-130. https://doi.org/10.1016/j.jarmac.2014.06.004

Sinclair, N., Chorney, S., \& Rodney, S. (2015). Rhythm in number: exploring the affective, social and mathematical dimensions of using TouchCounts. Mathematics Education Research Journal, 28(1), 31-51. https://doi.org/10.1007/s13394-015-0154-y

Sinclair, N., \& de Freitas, E. (2014). The haptic nature of gesture. Gesture, 14(3), 351-374. https://doi.org/10.1075/gest.14.3.04sin

Sinclair, N., \& Pimm, D. (2015). Mathematics using multiple senses: Developing finger gnosis with three- and four-year-olds in an era of multi-touch technologies. Asia-Pacific Journal of Research in Early Childhood Education, 9(3), 99-109.

Vygotsky, L. S. (1978). Mind in society: The development of higher psychological processes. Cambridge, MA: Harvard University Press.

Wood, D., Bruner, J. S., \& Ross, G. (1976). The role of tutoring in problem solving. Journal of Child Psychology and Psychiatry, 17(2), 89-100. https://doi.org/10.1111/j.14697610.1976.tb00381.x

Zhang, M., Trussell, R. P., Gallegos, B., \& Asam, R. R. (2015). Using math apps for improving student learning: An exploratory study in an inclusive fourth grade classroom.

TechTrends, 59(2), 32-39. https://doi.org/10.1007/s11528-015-0837-y 


\section{Appendix A}

Full Distance Data Tables

Table A1.

Degree of Mathematical and Technological Distance during Participant 7's Activity Involving DragonBox Algebra 12+ (Complete)

\begin{tabular}{|c|c|c|c|c|}
\hline \multirow[b]{2}{*}{ Attempt } & \multicolumn{2}{|c|}{ Level } & \multicolumn{2}{|c|}{ Distance } \\
\hline & Group & Number & Mathematical & Technological \\
\hline 1 & 1 & $1: 01$ & 4 & 4 \\
\hline 2 & 1 & $1: 02$ & 4 & 4 \\
\hline 3 & 2 & 1:03 & 4 & 4 \\
\hline 4 & 2 & 1:04 & 4 & 4 \\
\hline 5 & 2 & $1: 05$ & 3 & 4 \\
\hline 6 & 2 & 1:06 & 4 & 4 \\
\hline 7 & 2 & 1:07 & 2 & 4 \\
\hline 8 & 2 & $1: 08$ & 4 & 4 \\
\hline 9 & 3 & 1:09 & 4 & 4 \\
\hline 10 & 3 & $1: 10$ & 4 & 4 \\
\hline 11 & 3 & $1: 11$ & 4 & 4 \\
\hline 12 & 3 & $1: 12$ & 1 & 4 \\
\hline 13 & 3 & $1: 12$ & 3 & 4 \\
\hline 14 & 3 & $1: 13$ & 4 & 4 \\
\hline 15 & 3 & $1: 14$ & 1 & 4 \\
\hline 16 & 3 & $1: 14$ & 1 & 4 \\
\hline 17 & 3 & $1: 14$ & 1 & 4 \\
\hline 18 & 3 & $1: 14$ & 1 & 4 \\
\hline 19 & 3 & $1: 14$ & 1 & 4 \\
\hline 20 & 3 & $1: 14$ & 1 & 4 \\
\hline 21 & 3 & $1: 14$ & 1 & 4 \\
\hline 22 & 3 & $1: 14$ & 1 & 4 \\
\hline 23 & 3 & $1: 14$ & 1 & 4 \\
\hline 24 & 3 & $1: 14$ & 1 & 4 \\
\hline 25 & 3 & $1: 14$ & 1 & 4 \\
\hline 26 & 3 & $1: 14$ & 1 & 4 \\
\hline 27 & 3 & $1: 14$ & 1 & 4 \\
\hline 28 & 3 & $1: 14$ & 1 & 4 \\
\hline 29 & 3 & $1: 14$ & 1 & 4 \\
\hline 30 & 3 & $1: 14$ & 1 & 4 \\
\hline 31 & 3 & $1: 14$ & 4 & 4 \\
\hline 32 & 3 & $1: 15$ & 1 & 4 \\
\hline 33 & 3 & $1: 15$ & 2 & 4 \\
\hline
\end{tabular}




\begin{tabular}{lllll}
34 & 4 & $1: 16$ & 4 & 4 \\
35 & 4 & $1: 17$ & 2 & 4 \\
36 & 4 & $1: 18$ & 1 & 4 \\
37 & 4 & $1: 18$ & 1 & 4 \\
38 & 4 & $1: 18$ & 1 & 4 \\
39 & 4 & $1: 18$ & 1 & 4 \\
40 & 4 & $1: 18$ & 1 & 4 \\
41 & 4 & $1: 18$ & 1 & 4 \\
42 & 4 & $1: 18$ & 1 & 4 \\
43 & 4 & $1: 18$ & 4 & 4 \\
\hline
\end{tabular}

Note. Attempt denotes position in overall sequence of attempts to complete any level of DragonBox Algebra 12+. Level: Group denotes the set of related levels. Level: Number denotes the Chapter and Level within the chapter attempted. Distance: Mathematical denotes degree of mathematical distance. Distance: Technological denotes degree of technological distance.

Table A2.

Degree of Mathematical and Technological Distance during Participant 10's Activity Involving Motion Math: Zoom (Complete)

\begin{tabular}{rrrrrr} 
& \multicolumn{2}{c}{ Level } & \multicolumn{2}{c}{ Distance } \\
Attempt & Group & Number & Needle & Mathematical & Technological \\
\hline 1 & 1 & 1 & 0 & 4 & 4 \\
2 & 2 & 2 & 0 & 4 & 4 \\
3 & 2 & 3 & 0 & 4 & 4 \\
4 & 2 & 4 & 0 & 4 & 4 \\
5 & 2 & 5 & 0 & 3 & 4 \\
6 & 3 & 6 & 0 & 3 & 4 \\
7 & 6 & 15 & 1 & 1 & 3 \\
8 & 6 & 15 & 1 & 1 & 4 \\
9 & 6 & 15 & 1 & 1 & 3 \\
10 & 6 & 15 & 1 & 2 & 3 \\
11 & 6 & 15 & 1 & 2 & 3 \\
12 & 6 & 15 & 1 & 2 & 3 \\
13 & 6 & 15 & 1 & 2 & 3 \\
14 & 6 & 15 & 1 & 2 & 2 \\
15 & 6 & 15 & 1 & 1 & 2 \\
16 & 6 & 15 & 1 & 1 & 2 \\
17 & 6 & 15 & 1 & 2 & 3 \\
18 & 6 & 15 & 1 & 3 & 3 \\
19 & 6 & 15 & 1 & 2 & 3 \\
20 & 6 & 15 & 1 & 2 &
\end{tabular}


Note. Attempt denotes position in overall sequence of attempts to complete any level of Motion Math: Zoom. Level: Group denotes the set of related levels. Level: Number denotes the Level attempted. Needle denotes timer function; 0 is inactive, 1 is active. Distance: Mathematical denotes degree of mathematical distance. Distance: Technological denotes degree of technological distance. 


\section{Exploring the Phenomenon of Distance in Children's Interactions with Touchscreen Digital Mathematics Games}

Tables (all)

Table 1

Examples of Mathematical and Technological Distance

\begin{tabular}{ll}
\hline \multicolumn{1}{c}{ Motion Math: Zoom } & \multicolumn{1}{c}{ DragonBox Algebra 12+ } \\
\hline Mathematical distance: High degree & \\
$\begin{array}{l}\text { [Needle] popped first task (0.05); tried 0.5 } \\
\text { placement even after app filled the empty space } \\
\text { (P02 A8 L15N) }\end{array}$ & $\begin{array}{l}\text { Ends up adding all [variables] from outside and } \\
\text { trying to combine across or within for unlike } \\
\text { [variables]. (P03 A13 L1:12) }\end{array}$ \\
Mathematical distance: Low degree & \\
$\begin{array}{ll}\text { [Chooses] ideal intervals and ranges (P10 A4 } \\
\text { L4) }\end{array}$ & $\begin{array}{l}\text { Replicates solution. Audible deep sigh. (P07 A31 } \\
\text { L1:14) }\end{array}$
\end{tabular}

Technological distance: High degree

Mixed up zoom in/out gestures (P03 A8 L15N) Misses drag/drop again (P03 A6 L1:06)

Technological distance: Low degree

Controlled zooming when close to interval level Watches new power once, correctly replicates (P04 A8 L18)

tap. (P06 A28 L2:05)

Note. Alphanumeric sequences in parentheses indicate references to specific memos. $\mathrm{P}$ indicates participant, A indicates the attempt number, L indicates level or chapter and level. Brackets indicate clarifications. (Authors, 2015c, p. 83) 
Table 2

Examples of Changing Distance

\begin{tabular}{|c|c|}
\hline Motion Math: Zoom & DragonBox Algebra 12+ \\
\hline \multicolumn{2}{|l|}{ Mathematical distance: Decreasing } \\
\hline $\begin{array}{l}\text { P05 } \\
\text { Much L[eft]-R[ight] confusion.... Imprecise, } \\
\text { non-ideal choices... often travels for } \\
\text { extended time with inefficient interval, but } \\
\text { usually in correct direction (A11 L5) } \\
\text { - Chooses some inefficient intervals... to } \\
\text { travel within... [but] accurate completion } \\
\text { (A12 L6) }\end{array}$ & $\begin{array}{l}\text { P09 } \\
\text { Begins with incorrect unneeded addition } \\
\text { variable.... Eventually places all variables } \\
\text { and attempts some impossible combos. (A11 } \\
\text { L1:11) } \\
\text { - Quickly correct and complete. (A12 L1:11) }\end{array}$ \\
\hline \multicolumn{2}{|l|}{ Mathematical distance: Increasing } \\
\hline $\begin{array}{l}\text { P06 } \\
\text { Correct/ideal for } 0.05 \ldots . \text { For } 1.00 \text { to } 1.53 \text {, } \\
\text { chooses appropriate place to zoom in.... } \\
\text { Balance of sufficient accuracy with lots of } \\
\text { speed--and memory of type of upcoming task } \\
\text { for planning. (A17 L15N) } \\
\text { - } 0.10 \text { from tenths }(0.7) \text {--right first, then } \\
\text { zoomed in at } 0.5 \text { to travel by hundredths. } \\
\text { (A18 L16N) }\end{array}$ & $\begin{array}{l}\text { P04 } \\
\text { - Combo inside, direct combo from outside } \\
\text { [completes simplified solution] (A15 L1:14) } \\
\text { - Direct combo from outside... [does not } \\
\text { simplify] opposite side (A16 L1:15) }\end{array}$ \\
\hline \multicolumn{2}{|l|}{ Technological distance: Decreasing } \\
\hline $\begin{array}{l}\text { P03 } \\
\text { - Struggled to zoom out [because] of mixing } \\
\text { up zoom in/out gestures. (A13 L15N) } \\
\text { - Zoomed out for } 0.3 \text { with multiple intervals } \\
\text { showing. Zoomed in for } 0.04 \text { at } 0.1-0.2 \ldots \\
\text { [No] in/out mixups. (A14 L15N) }\end{array}$ & $\begin{array}{l}\text { P02 } \\
\text { - Swipe swirls [instead of tap], app did not read } \\
\text { every time (A5 L1:05) } \\
\text { - Now using correct tech input (A12 L1:12) }\end{array}$ \\
\hline \multicolumn{2}{|l|}{ Technological distance: Increasing } \\
\hline $\begin{array}{l}\text { P08 } \\
\text { - Thumb swipe at corner of screen for } 5,21 \text {, } \\
\text { 12. Scaffolded zoom for } 15 . \text { (A1 L1) } \\
\text { - Nearly vertical zoom... slows progress.... } \\
\text { Scaffolded zoom in replication difficulties.... } \\
\text { For } 0.01 \text { from } 1 . X X \text {, travels by hundredths. } \\
\text { Tries to zoom out but fails. (A2 L15) }\end{array}$ & $\begin{array}{l}\text { P10 } \\
\text { - While holding [variable], sees white highlight } \\
\text { on [inverse], drags closer, sees yellow } \\
\text { highlight, combines (A38 L2:13) } \\
\text { - Some gestures misread or placed/executed } \\
\text { poorly (A39 L2:13) }\end{array}$ \\
\hline
\end{tabular}

Note: Alphanumeric sequences in parentheses indicate references to specific memos. $\mathrm{P}$ indicates participant, A indicates the attempt number, L indicates level or chapter and level. Brackets indicate clarifications. (Authors, 2015c, p. 86) 
Table 3

Interplay between Mathematical Distance and Technological Distance

\begin{tabular}{|c|c|}
\hline Motion Math: Zoom & DragonBox Algebra 12+ \\
\hline P03 & $\mathrm{P} 02$ \\
\hline \multirow{2}{*}{$\begin{array}{l}\text { Gesture is two-hand mostly horizontal and } \\
\text { quick--app struggles to read at times (may } \\
\text { touch too lightly?). Chooses correct interval for } \\
\text { zooming, but zoom becomes diagonal and } \\
\text { [difficult] for app to recognize (A4 L4) }\end{array}$} & \multirow{2}{*}{$\begin{array}{l}\text { - Tries to divide by appropriate [variable] but } \\
\text { misses--ends up then trying to [add] (A35 } \\
\text { L2:13) } \\
\text { - Tries to use two [variables] at the same time } \\
\text { (multi-touch) (A40 L2:13) }\end{array}$} \\
\hline & \\
\hline \multirow{2}{*}{\multicolumn{2}{|c|}{$\begin{array}{l}\text { - Reverses zoom in/out gestures and ends up } \\
\text { traveling at inefficient interval (A6 L6) } \\
\text { " } \text { "I knew the math, but the zooming in and } \\
\text { zooming out part is hard." (ZFT) }\end{array}$}} \\
\hline & \\
\hline $\mathrm{P} 07$ & P06 \\
\hline \multirow{3}{*}{$\begin{array}{l}\text { - "In between zero and one there is a certain } \\
\text { amount of hundredths... [For] one and sixty- } \\
\text { sixty hundredths, I would go past one and } \\
\text { estimate about how far past the bee would I } \\
\text { zoom in to get onto the little ants. If I got } \\
\text { farther then I might have got to thousandths." } \\
\text { (P07 ZFT) }\end{array}$} & $\begin{array}{l}\text { Multiple extra one-dot [coefficients made] } \\
\text { when drag/tap input mistakes. Ends up with } \\
\text { extra moves. (A32 L2:09) }\end{array}$ \\
\hline & $\begin{array}{l}\text { - Creates extra one-dot [coefficients] while } \\
\text { trying to combine variables before clearing } \\
\text { [coefficient] (A33 L2:10) }\end{array}$ \\
\hline & $\begin{array}{l}\text { Accidentally makes one-dot [coefficient] } \\
\text { while trying to drag (A36 L2:12) }\end{array}$ \\
\hline
\end{tabular}

Note. Alphanumeric sequences in parentheses indicate references to specific memos. P indicates participant, A indicates the attempt number, L indicates level or chapter and level. ZFT indicates Motion Math: Zoom Follow-Up Questions Transcript. Quotation marks indicate direct quotes from participants. Brackets indicate clarifications. (Adapted from Authors, 2015c, p. 104) 
Table 4.

Degree of Mathematical and Technological Distance during Participant 7 's Activity Involving DragonBox Algebra 12+ (Excerpts)

\begin{tabular}{|c|c|c|c|c|}
\hline \multirow[b]{2}{*}{ Attempt } & \multicolumn{2}{|c|}{ Level } & \multicolumn{2}{|c|}{ Distance } \\
\hline & Group & Number & Mathematical & Technological \\
\hline 1 & 1 & $1: 01$ & 4 & 4 \\
\hline 2 & 1 & $1: 02$ & 4 & 4 \\
\hline 3 & 2 & $1: 03$ & 4 & 4 \\
\hline 4 & 2 & $1: 04$ & 4 & 4 \\
\hline 5 & 2 & $1: 05$ & 3 & 4 \\
\hline 6 & 2 & $1: 06$ & 4 & 4 \\
\hline 7 & 2 & $1: 07$ & 2 & 4 \\
\hline 8 & 2 & $1: 08$ & 4 & 4 \\
\hline 9 & 3 & $1: 09$ & 4 & 4 \\
\hline 10 & 3 & $1: 10$ & 4 & 4 \\
\hline 11 & 3 & $1: 11$ & 4 & 4 \\
\hline 12 & 3 & $1: 12$ & 1 & 4 \\
\hline 13 & 3 & $1: 12$ & 3 & 4 \\
\hline 14 & 3 & $1: 13$ & 4 & 4 \\
\hline 15 & 3 & $1: 14$ & 1 & 4 \\
\hline 29 & 3 & $1: 14$ & 1 & 4 \\
\hline 30 & 3 & $1: 14$ & 1 & 4 \\
\hline 31 & 3 & $1: 14$ & 4 & 4 \\
\hline 32 & 3 & $1: 15$ & 1 & 4 \\
\hline 33 & 3 & $1: 15$ & 2 & 4 \\
\hline 34 & 4 & $1: 16$ & 4 & 4 \\
\hline 35 & 4 & $1: 17$ & 2 & 4 \\
\hline 36 & 4 & $1: 18$ & 1 & 4 \\
\hline 42 & 4 & $1: 18$ & 1 & 4 \\
\hline 43 & 4 & $1: 18$ & 4 & 4 \\
\hline
\end{tabular}

Note. Attempt denotes position in overall sequence of attempts to complete any level of DragonBox Algebra 12+. Level: Group denotes the set of related levels. Level: Number denotes the Chapter and Level within the chapter attempted. Distance: Mathematical denotes degree of mathematical distance. Distance: Technological denotes degree of technological distance. Full table including all attempts appears in Appendix A, Table A1. 
Table 5 .

Degree of Mathematical and Technological Distance during Participant 10's Activity Involving Motion Math: Zoom (Excerpts)

\begin{tabular}{rrrrrr}
\multicolumn{5}{c}{ Level } & \multicolumn{3}{c}{ Distance } \\
Attempt & Group & Number & Needle & Mathematical & Technological \\
\hline 1 & 1 & 1 & 0 & 4 & 4 \\
2 & 2 & 2 & 0 & 4 & 4 \\
3 & 2 & 3 & 0 & 4 & 4 \\
4 & 2 & 4 & 0 & 4 & 4 \\
5 & 2 & 5 & 0 & 3 & 4 \\
6 & 3 & 6 & 0 & 3 & 4 \\
7 & 6 & 15 & 1 & 1 & 3 \\
8 & 6 & 15 & 1 & 1 & 4 \\
9 & 6 & 15 & 1 & 1 & 3 \\
10 & 6 & 15 & 1 & 2 & 3 \\
26 & 6 & 15 & 1 & 2 & 4 \\
27 & 6 & 15 & 1 & 2 & 4 \\
28 & 6 & 15 & 1 & 2 & 3 \\
29 & 6 & 15 & 1 & 2 & 4 \\
30 & 6 & 15 & 1 & 3 & 4 \\
31 & 6 & 15 & 1 & 4 & 4 \\
32 & 6 & 16 & 1 & 1 & 4 \\
33 & 6 & 16 & 1 & 1 & 4 \\
43 & 6 & 16 & 1 & 1 & 4 \\
44 & 6 & 16 & 1 & 2 & 4
\end{tabular}

Note. Attempt denotes position in overall sequence of attempts to complete any level of the Motion Math: Zoom. Level: Group denotes the set of related levels. Level: Number denotes the Level attempted. Needle denotes timer function; 0 is inactive, 1 is active. Distance: Mathematical denotes degree of mathematical distance. Distance: Technological denotes degree of technological distance. Full table including all attempts appears in Appendix A, Table A2. 


\section{Appendix A}

Full Distance Data Tables

Table A1.

Degree of Mathematical and Technological Distance during Participant 7's Activity Involving DragonBox Algebra 12+ (Complete)

\begin{tabular}{|c|c|c|c|c|}
\hline \multirow[b]{2}{*}{ Attempt } & \multicolumn{2}{|c|}{ Level } & \multicolumn{2}{|c|}{ Distance } \\
\hline & Group & Number & Mathematical & Technological \\
\hline 1 & 1 & 1:01 & 4 & 4 \\
\hline 2 & 1 & $1: 02$ & 4 & 4 \\
\hline 3 & 2 & 1:03 & 4 & 4 \\
\hline 4 & 2 & 1:04 & 4 & 4 \\
\hline 5 & 2 & $1: 05$ & 3 & 4 \\
\hline 6 & 2 & 1:06 & 4 & 4 \\
\hline 7 & 2 & 1:07 & 2 & 4 \\
\hline 8 & 2 & 1:08 & 4 & 4 \\
\hline 9 & 3 & 1:09 & 4 & 4 \\
\hline 10 & 3 & $1: 10$ & 4 & 4 \\
\hline 11 & 3 & $1: 11$ & 4 & 4 \\
\hline 12 & 3 & $1: 12$ & 1 & 4 \\
\hline 13 & 3 & $1: 12$ & 3 & 4 \\
\hline 14 & 3 & $1: 13$ & 4 & 4 \\
\hline 15 & 3 & $1: 14$ & 1 & 4 \\
\hline 16 & 3 & $1: 14$ & 1 & 4 \\
\hline 17 & 3 & $1: 14$ & 1 & 4 \\
\hline 18 & 3 & $1: 14$ & 1 & 4 \\
\hline 19 & 3 & $1: 14$ & 1 & 4 \\
\hline 20 & 3 & $1: 14$ & 1 & 4 \\
\hline 21 & 3 & $1: 14$ & 1 & 4 \\
\hline 22 & 3 & $1: 14$ & 1 & 4 \\
\hline 23 & 3 & $1: 14$ & 1 & 4 \\
\hline 24 & 3 & $1: 14$ & 1 & 4 \\
\hline 25 & 3 & $1: 14$ & 1 & 4 \\
\hline 26 & 3 & $1: 14$ & 1 & 4 \\
\hline 27 & 3 & $1: 14$ & 1 & 4 \\
\hline 28 & 3 & $1: 14$ & 1 & 4 \\
\hline 29 & 3 & $1: 14$ & 1 & 4 \\
\hline 30 & 3 & $1: 14$ & 1 & 4 \\
\hline 31 & 3 & $1: 14$ & 4 & 4 \\
\hline 32 & 3 & $1: 15$ & 1 & 4 \\
\hline 33 & 3 & $1: 15$ & 2 & 4 \\
\hline
\end{tabular}




\begin{tabular}{lllll}
34 & 4 & $1: 16$ & 4 & 4 \\
35 & 4 & $1: 17$ & 2 & 4 \\
36 & 4 & $1: 18$ & 1 & 4 \\
37 & 4 & $1: 18$ & 1 & 4 \\
38 & 4 & $1: 18$ & 1 & 4 \\
39 & 4 & $1: 18$ & 1 & 4 \\
40 & 4 & $1: 18$ & 1 & 4 \\
41 & 4 & $1: 18$ & 1 & 4 \\
42 & 4 & $1: 18$ & 1 & 4 \\
43 & 4 & $1: 18$ & 4 & 4 \\
\hline
\end{tabular}

Note. Attempt denotes position in overall sequence of attempts to complete any level of DragonBox Algebra 12+. Level: Group denotes the set of related levels. Level: Number denotes the Chapter and Level within the chapter attempted. Distance: Mathematical denotes degree of mathematical distance. Distance: Technological denotes degree of technological distance.

Table A2.

Degree of Mathematical and Technological Distance during Participant 10's Activity Involving Motion Math: Zoom (Complete)

\begin{tabular}{rrrrrr}
\multicolumn{5}{c}{ Level } & \multicolumn{3}{c}{ Distance } \\
Attempt & Group & Number & Needle & Mathematical & Technological \\
\hline 1 & 1 & 1 & 0 & 4 & 4 \\
2 & 2 & 2 & 0 & 4 & 4 \\
3 & 2 & 3 & 0 & 4 & 4 \\
4 & 2 & 4 & 0 & 4 & 4 \\
5 & 2 & 5 & 0 & 3 & 4 \\
6 & 3 & 6 & 0 & 3 & 4 \\
7 & 6 & 15 & 1 & 1 & 3 \\
8 & 6 & 15 & 1 & 1 & 4 \\
9 & 6 & 15 & 1 & 1 & 3 \\
10 & 6 & 15 & 1 & 2 & 3 \\
11 & 6 & 15 & 1 & 2 & 3 \\
12 & 6 & 15 & 1 & 2 & 3 \\
13 & 6 & 15 & 1 & 2 & 3 \\
14 & 6 & 15 & 1 & 2 & 2 \\
15 & 6 & 15 & 1 & 1 & 2 \\
16 & 6 & 15 & 1 & 1 & 2 \\
17 & 6 & 15 & 1 & 2 & 3 \\
18 & 6 & 15 & 1 & 3 & 3 \\
19 & 6 & 15 & 1 & 2 & 2 \\
20 & 6 & 15 & 1 & & 2
\end{tabular}




\begin{tabular}{llllll}
21 & 6 & 15 & 1 & 2 & 3 \\
22 & 6 & 15 & 1 & 1 & 3 \\
23 & 6 & 15 & 1 & 2 & 4 \\
24 & 6 & 15 & 1 & 2 & 3 \\
25 & 6 & 15 & 1 & 2 & 4 \\
26 & 6 & 15 & 1 & 2 & 4 \\
27 & 6 & 15 & 1 & 2 & 4 \\
28 & 6 & 15 & 1 & 2 & 3 \\
29 & 6 & 15 & 1 & 2 & 4 \\
30 & 6 & 15 & 1 & 3 & 4 \\
31 & 6 & 15 & 1 & 4 & 4 \\
32 & 6 & 16 & 1 & 1 & 4 \\
33 & 6 & 16 & 1 & 1 & 4 \\
34 & 6 & 16 & 1 & 1 & 4 \\
35 & 6 & 16 & 1 & 2 & 4 \\
36 & 6 & 16 & 1 & 1 & 4 \\
37 & 6 & 16 & 1 & 1 & 4 \\
38 & 6 & 16 & 1 & 1 & 4 \\
39 & 6 & 16 & 1 & 1 & 4 \\
40 & 6 & 16 & 1 & 1 & 4 \\
41 & 6 & 16 & 1 & 1 & 4 \\
42 & 6 & 16 & 1 & 1 & 4 \\
43 & 6 & 16 & 1 & 1 & 4 \\
44 & 6 & 16 & 1 & 2 & 4 \\
\hline
\end{tabular}

Note. Attempt denotes position in overall sequence of attempts to complete any level of Motion Math: Zoom. Level: Group denotes the set of related levels. Level: Number denotes the Level attempted. Needle denotes timer function; 0 is inactive, 1 is active. Distance: Mathematical denotes degree of mathematical distance. Distance: Technological denotes degree of technological distance. 
Figure(s) 1

Click here to download high resolution image

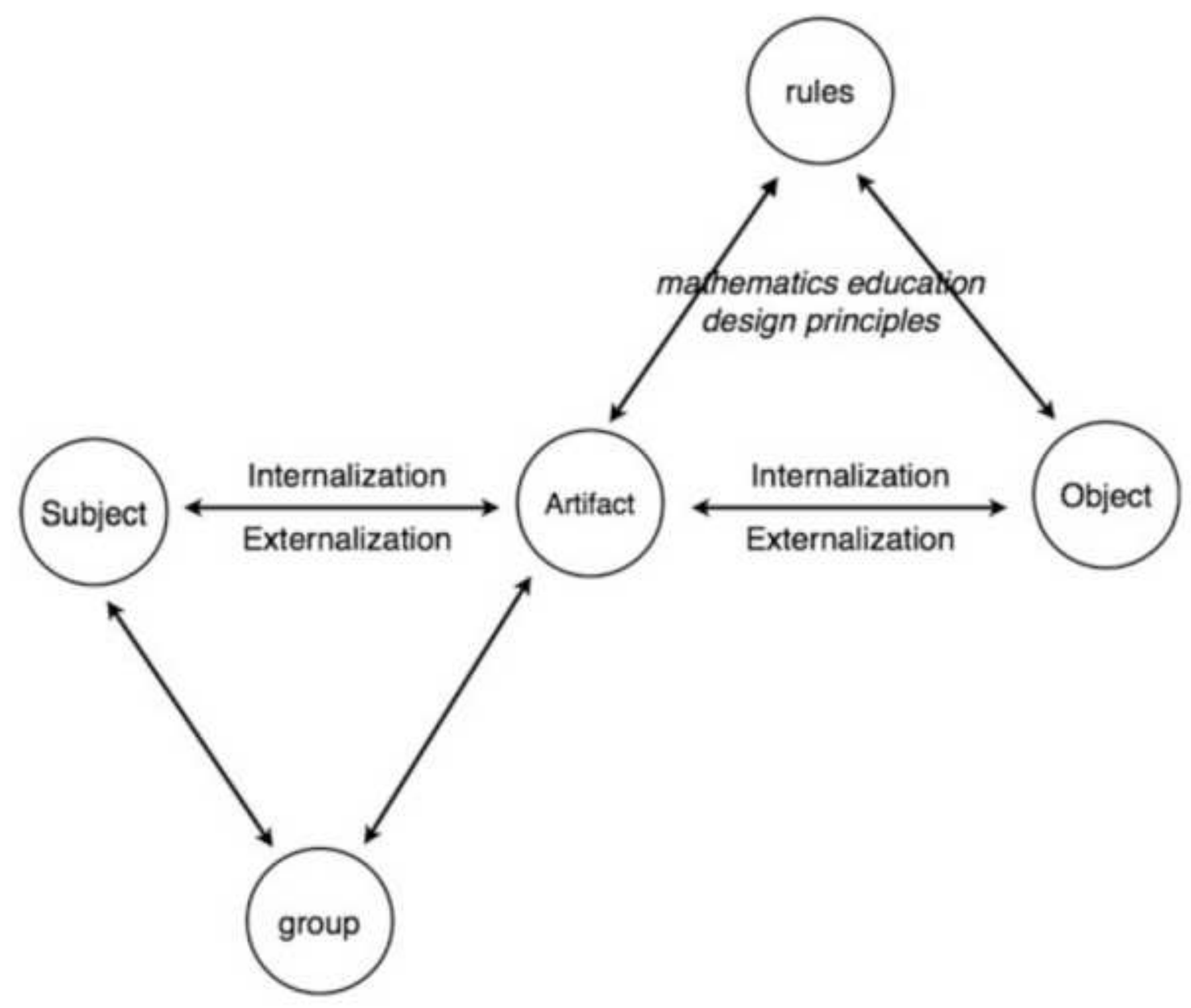


Figure(s) 2
Click here to download high resolution image

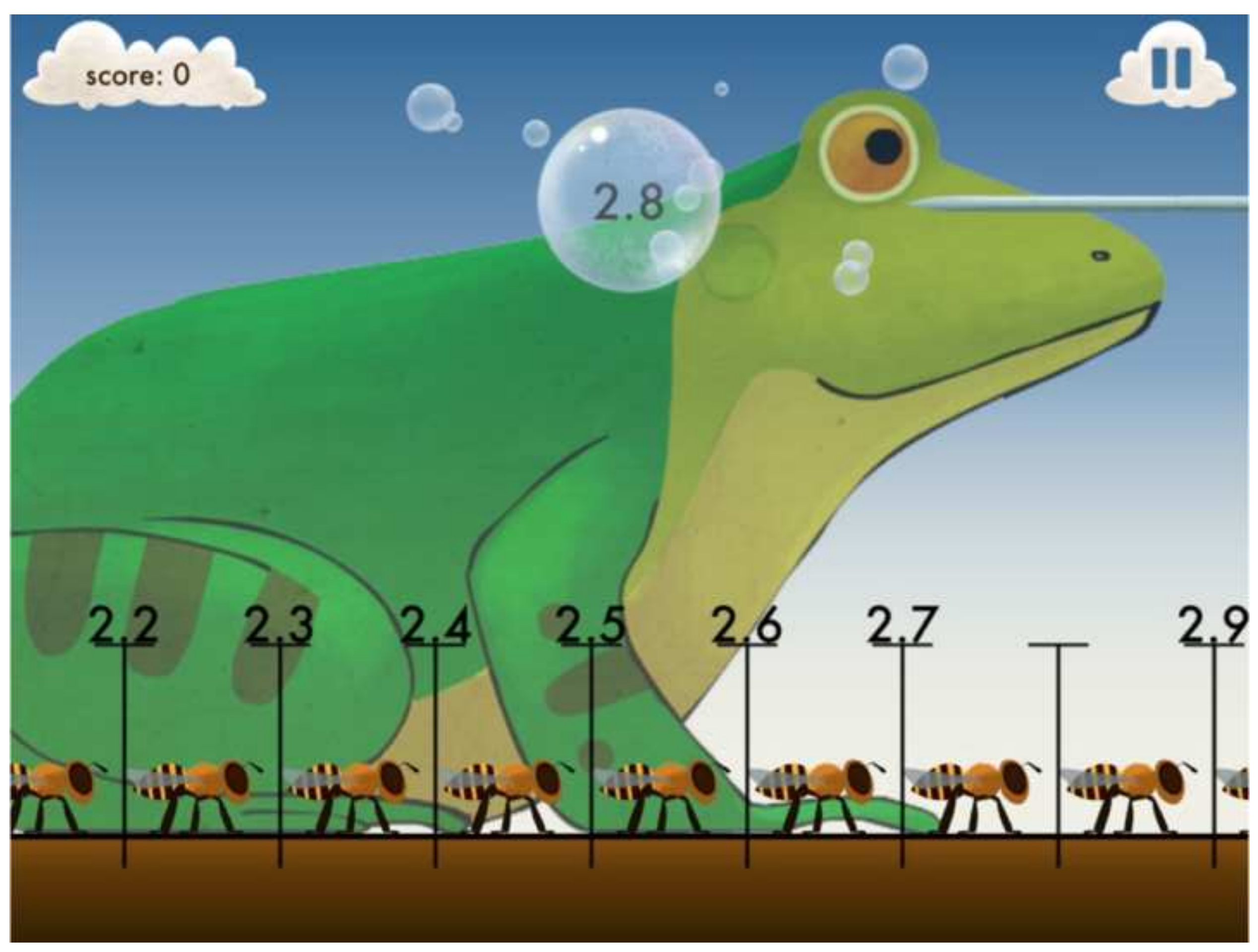


Figure(s) 3

Click here to download high resolution image

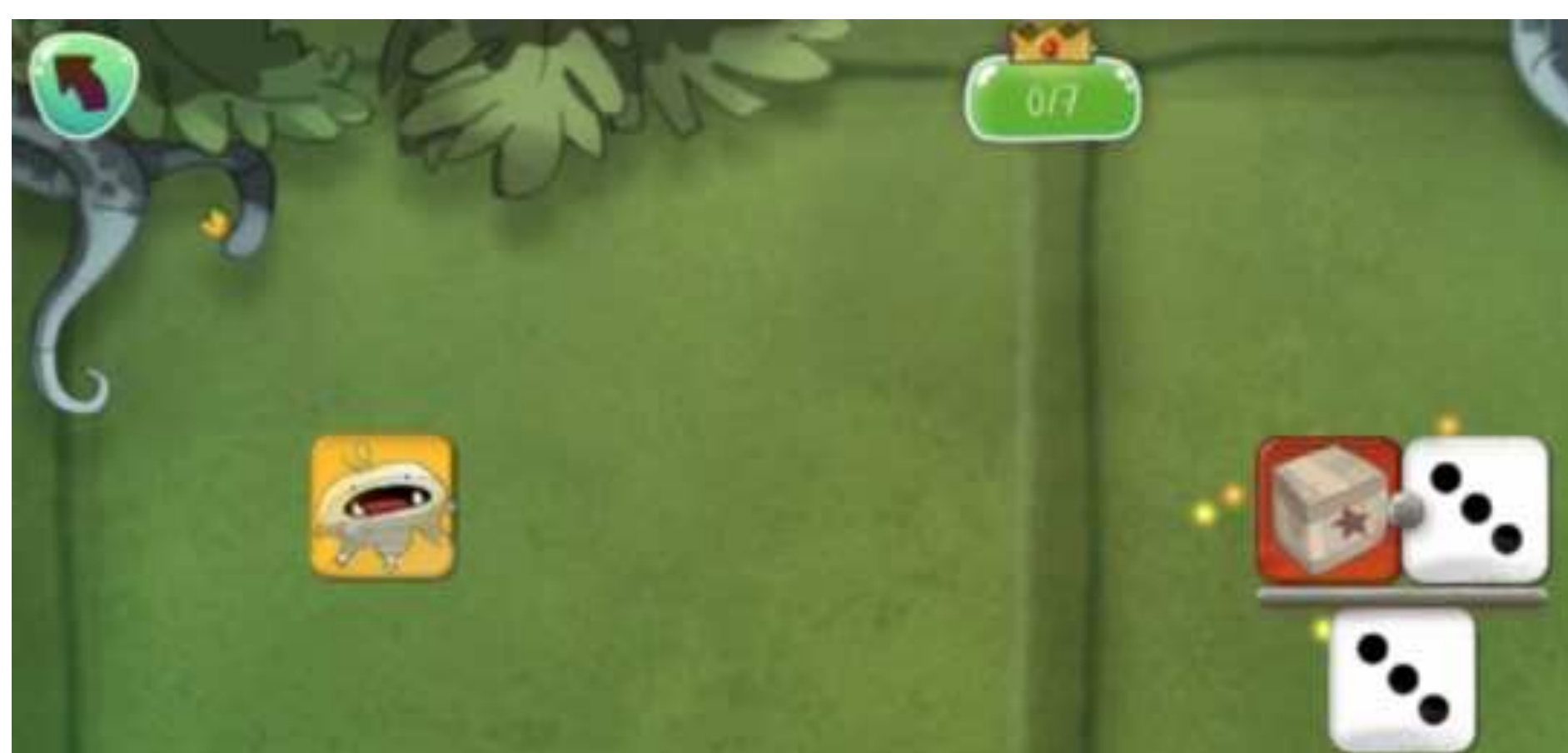


Figure(s)

Click here to download high resolution image

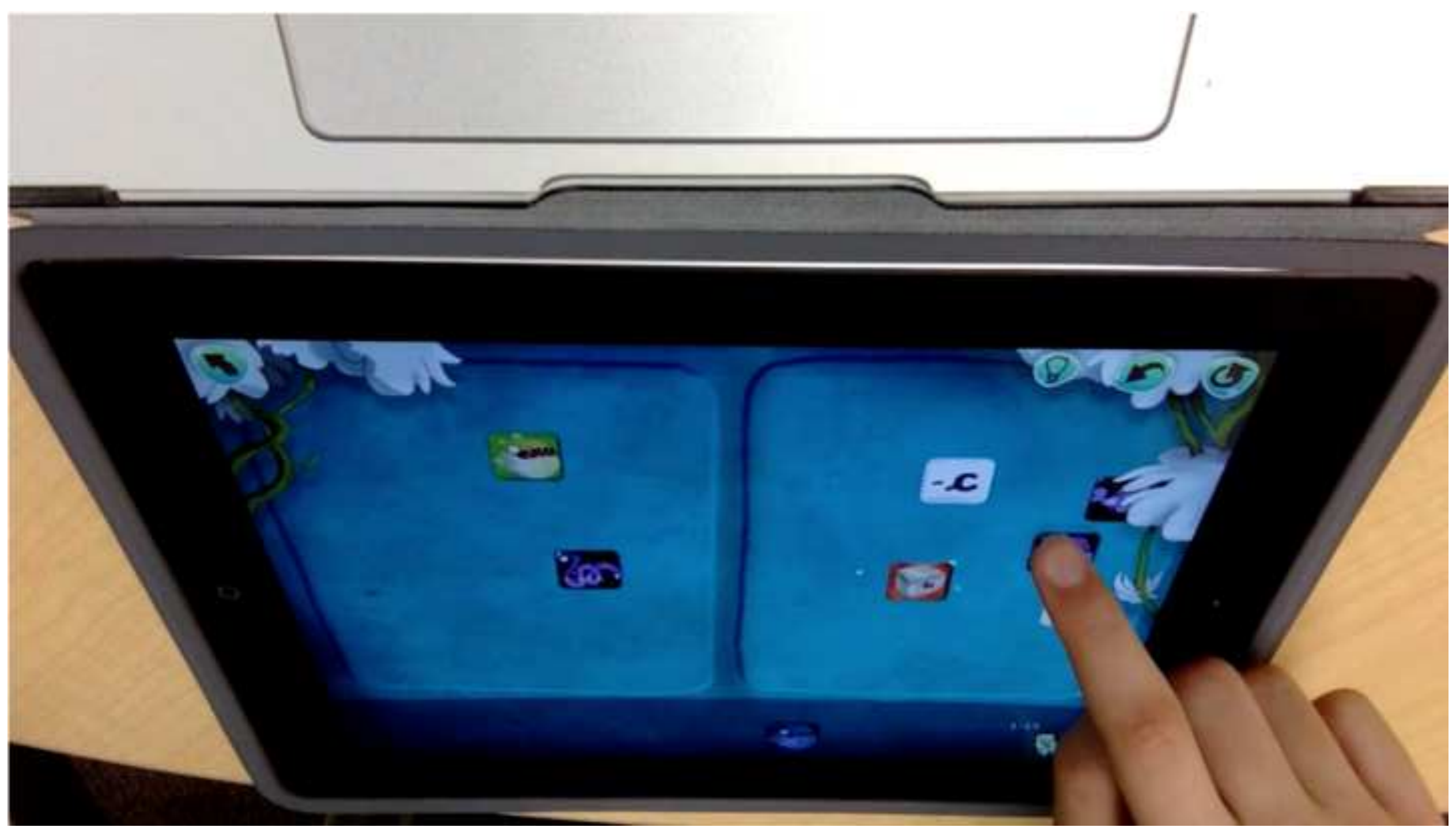


Click here to download high resolution image

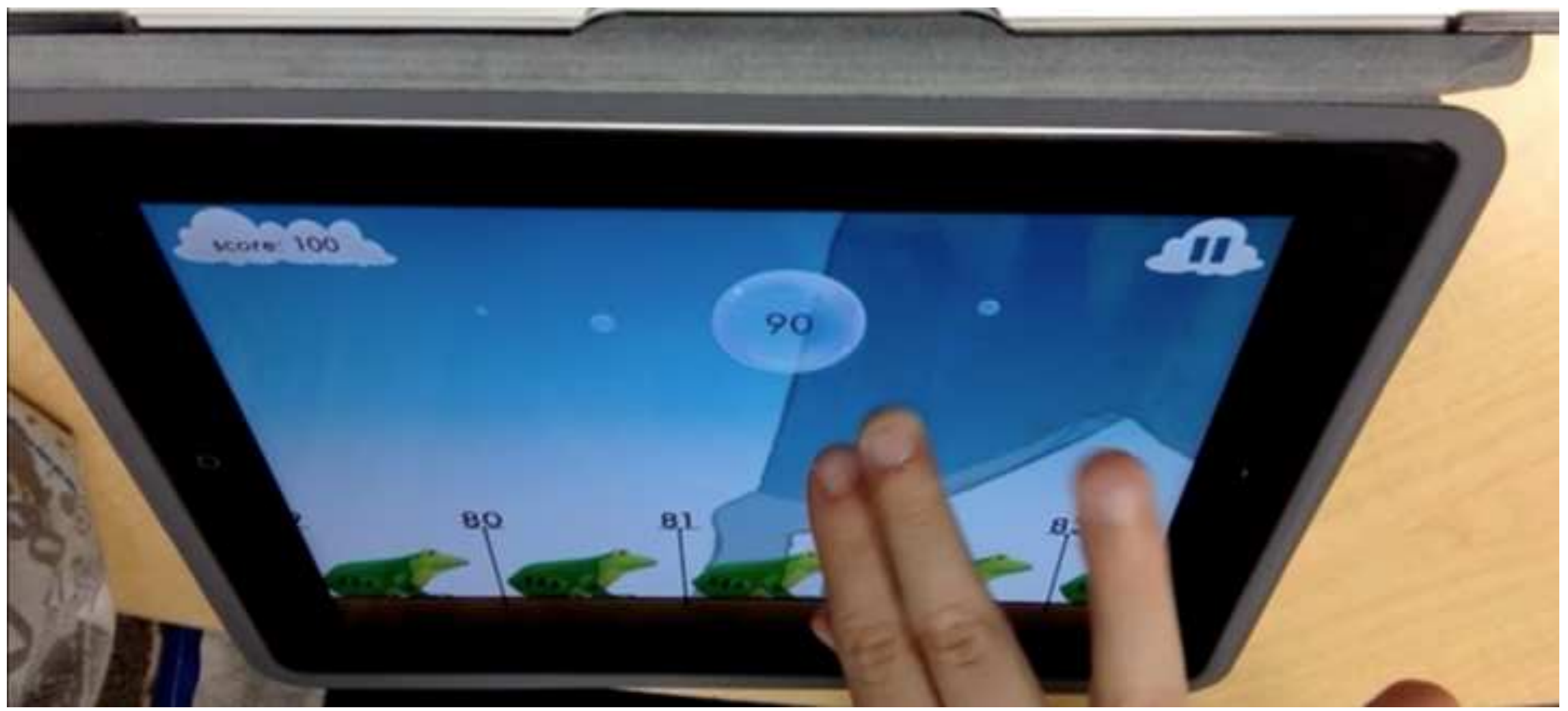


Click here to download high resolution image

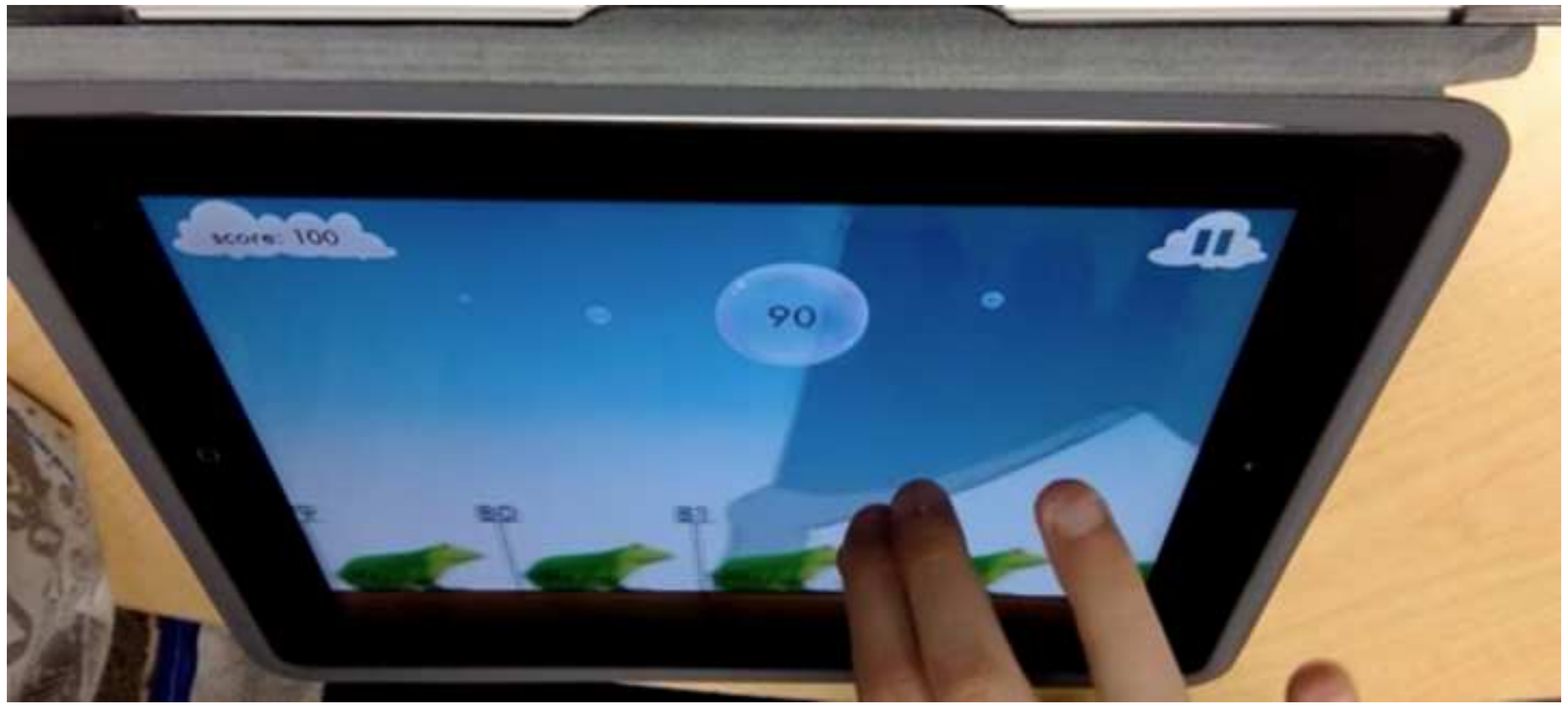




\section{gure(s) $5 c$}

Click here to download high resolution image

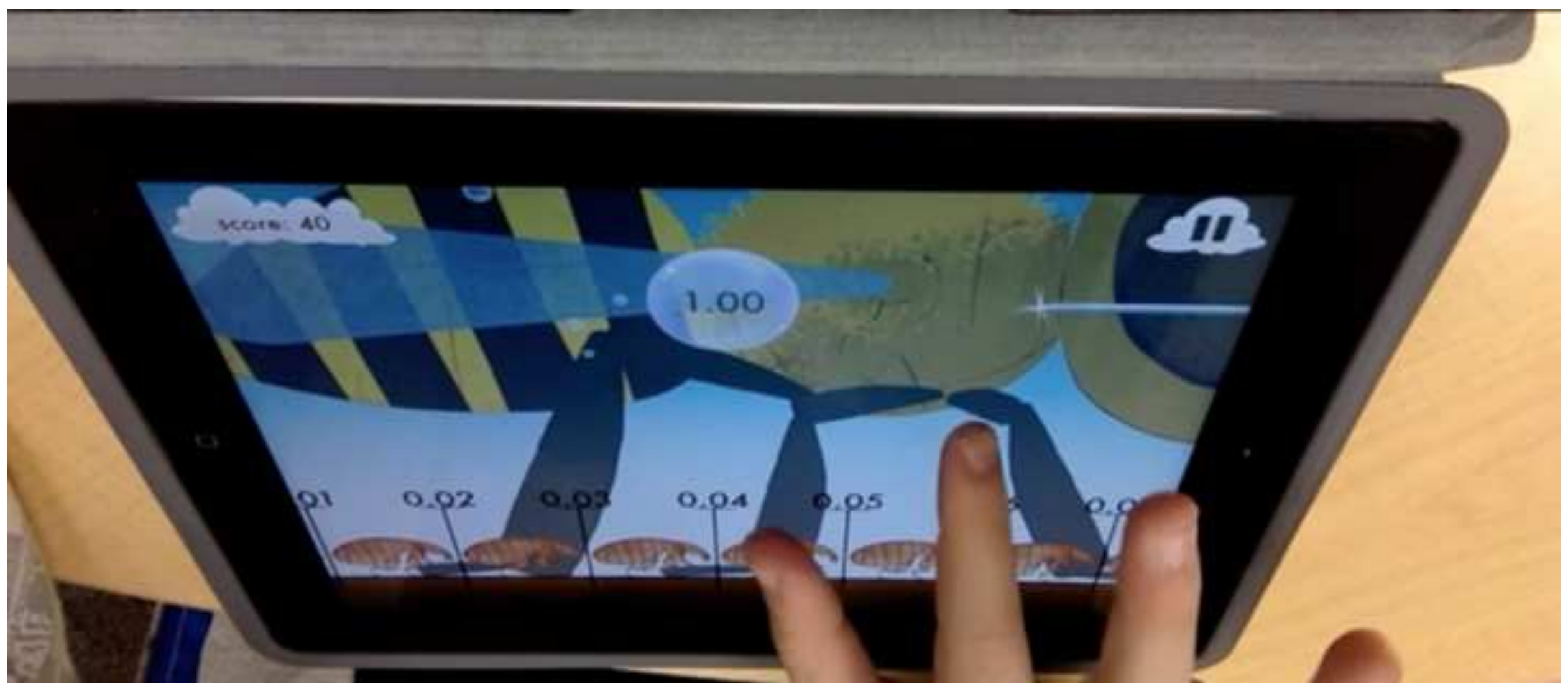




\section{Figure(s) $5 d$}

Click here to download high resolution image

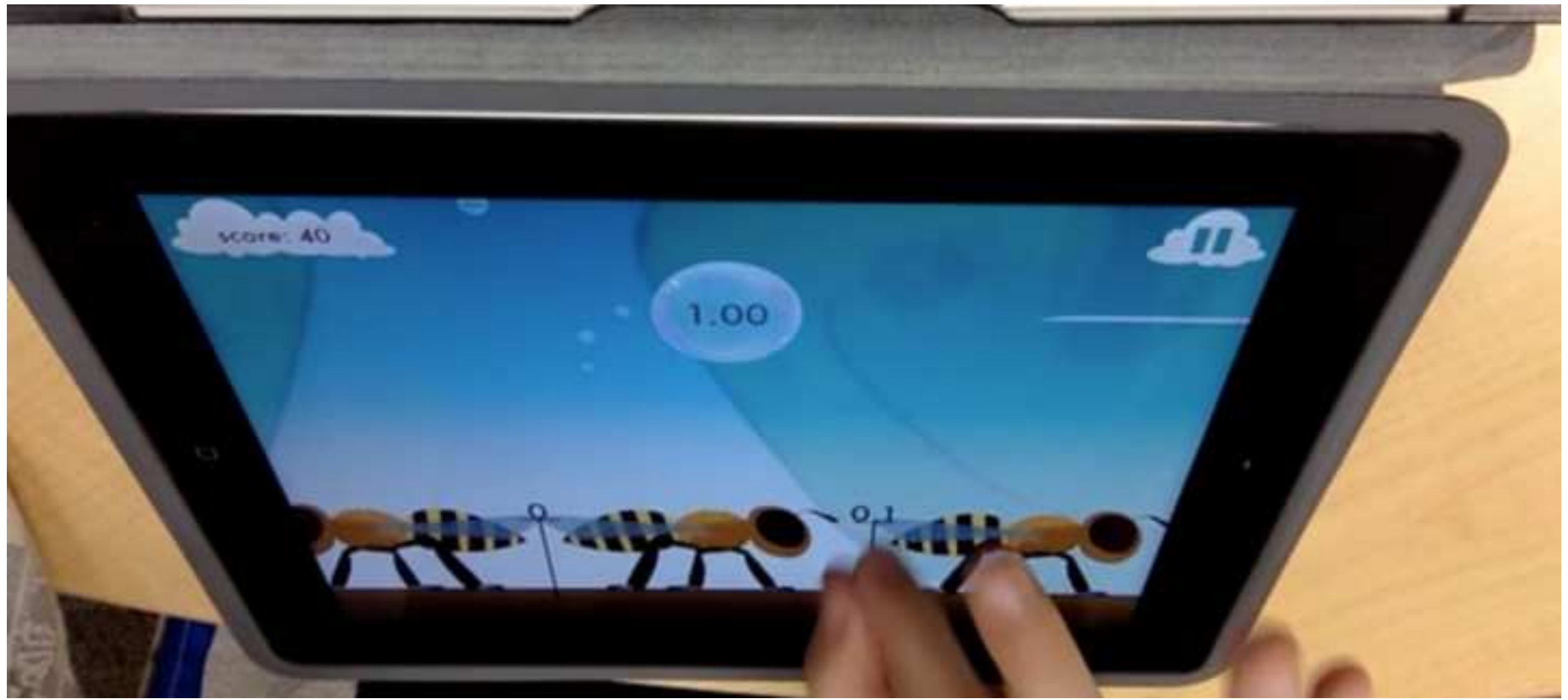


Figure(s) $6 a$
Click here to download high resolution image

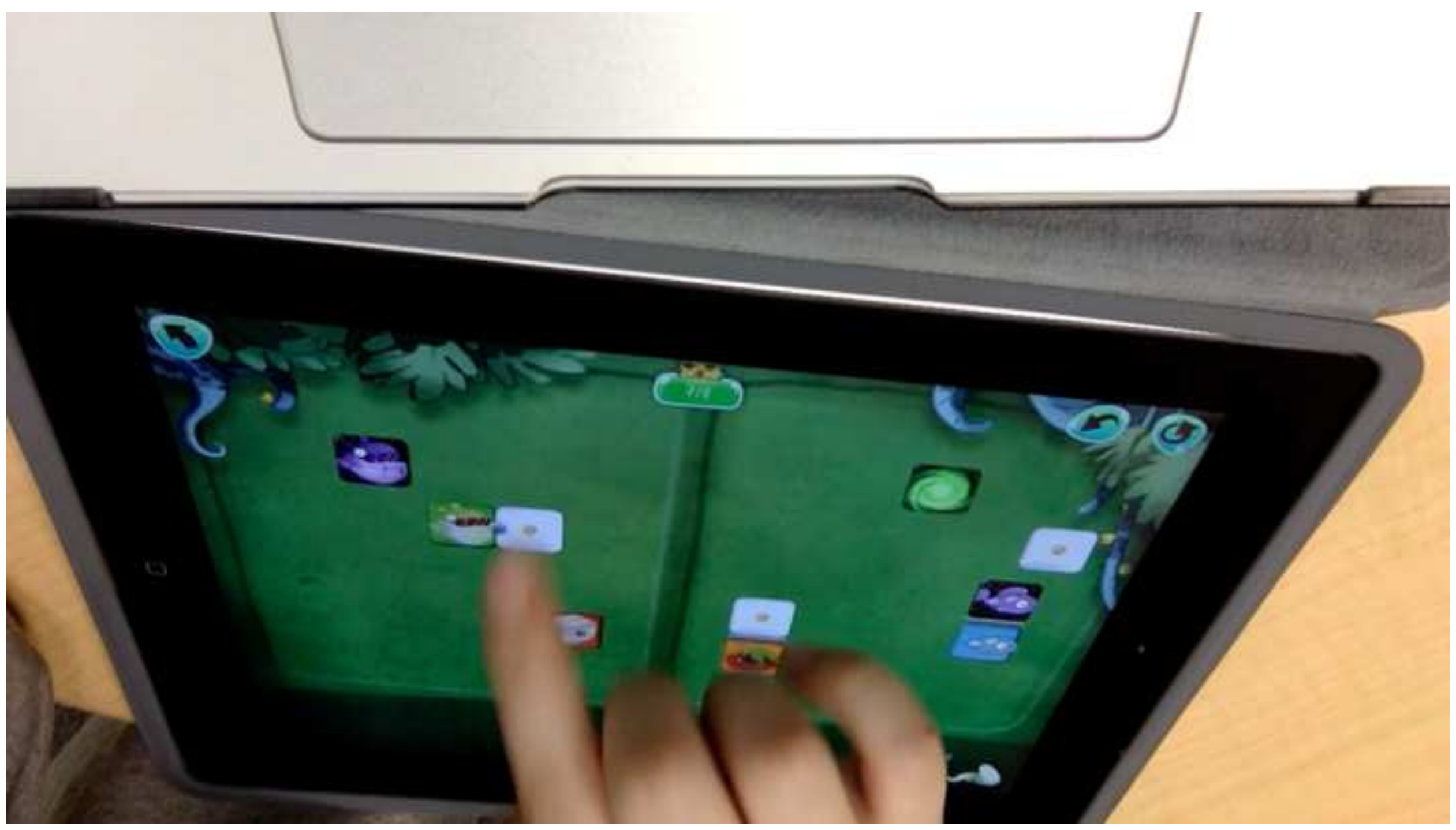


Click here to download high resolution image

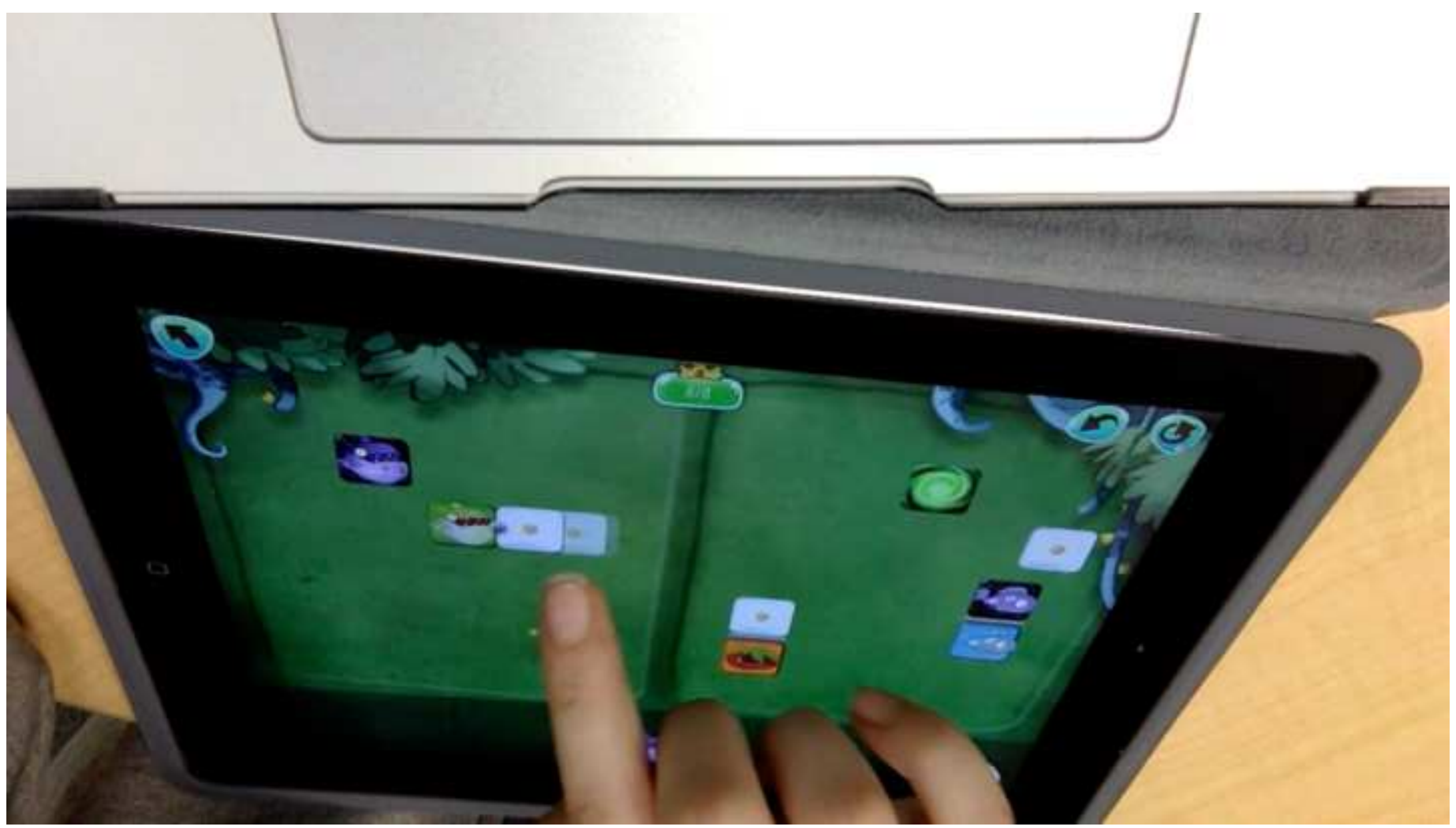


Click here to download high resolution image

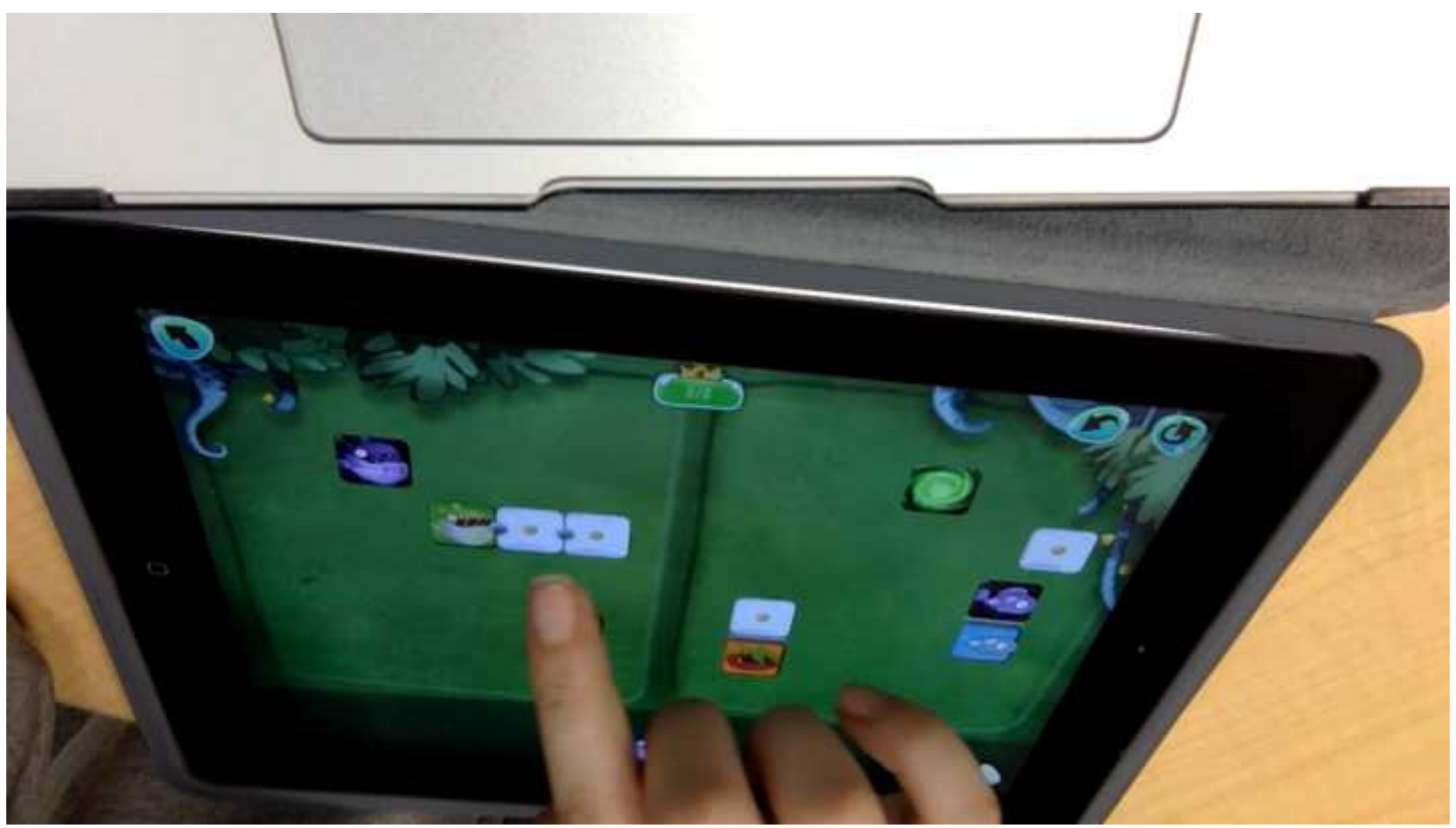


Click here to download high resolution image

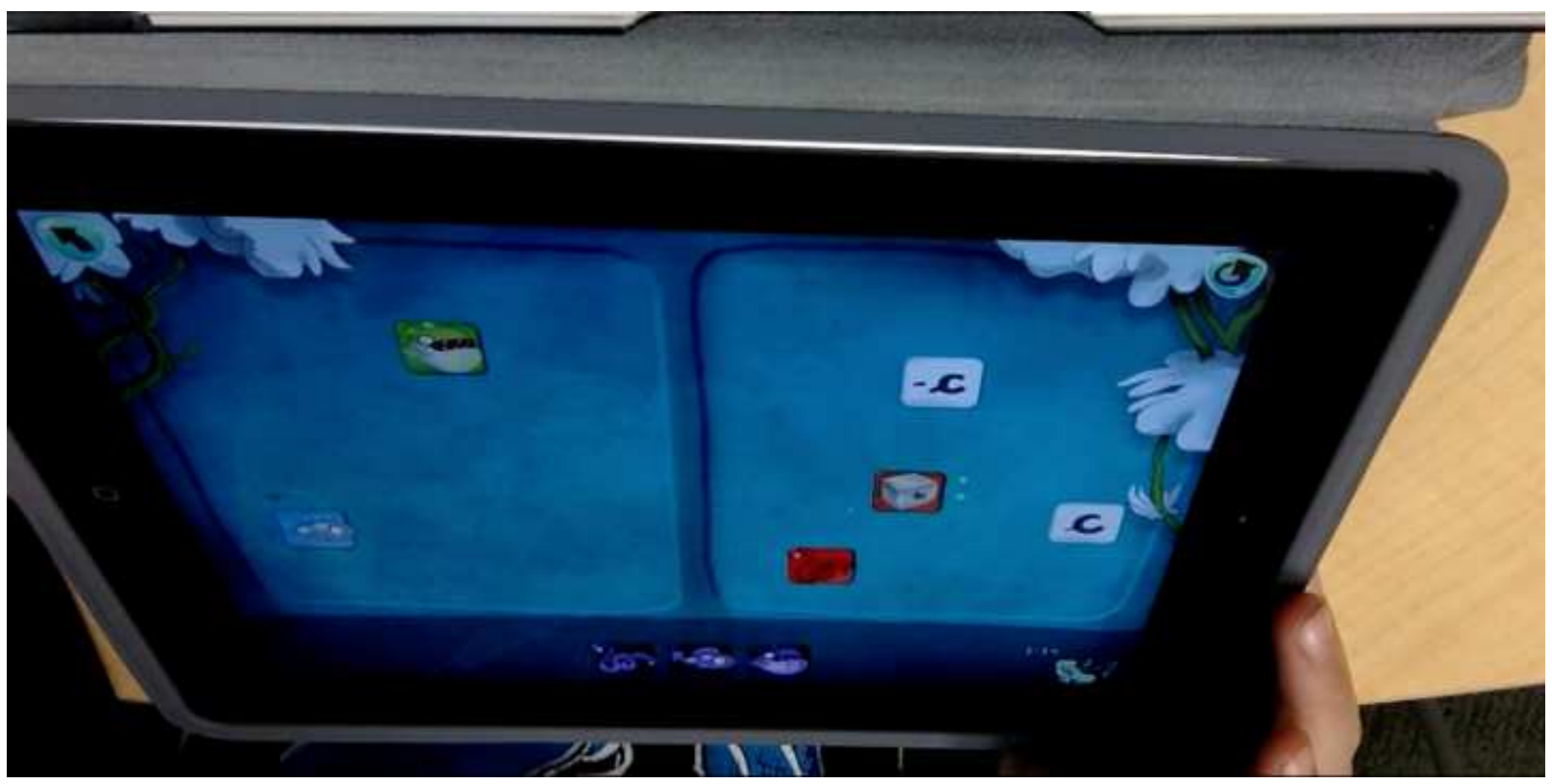


Click here to download high resolution image

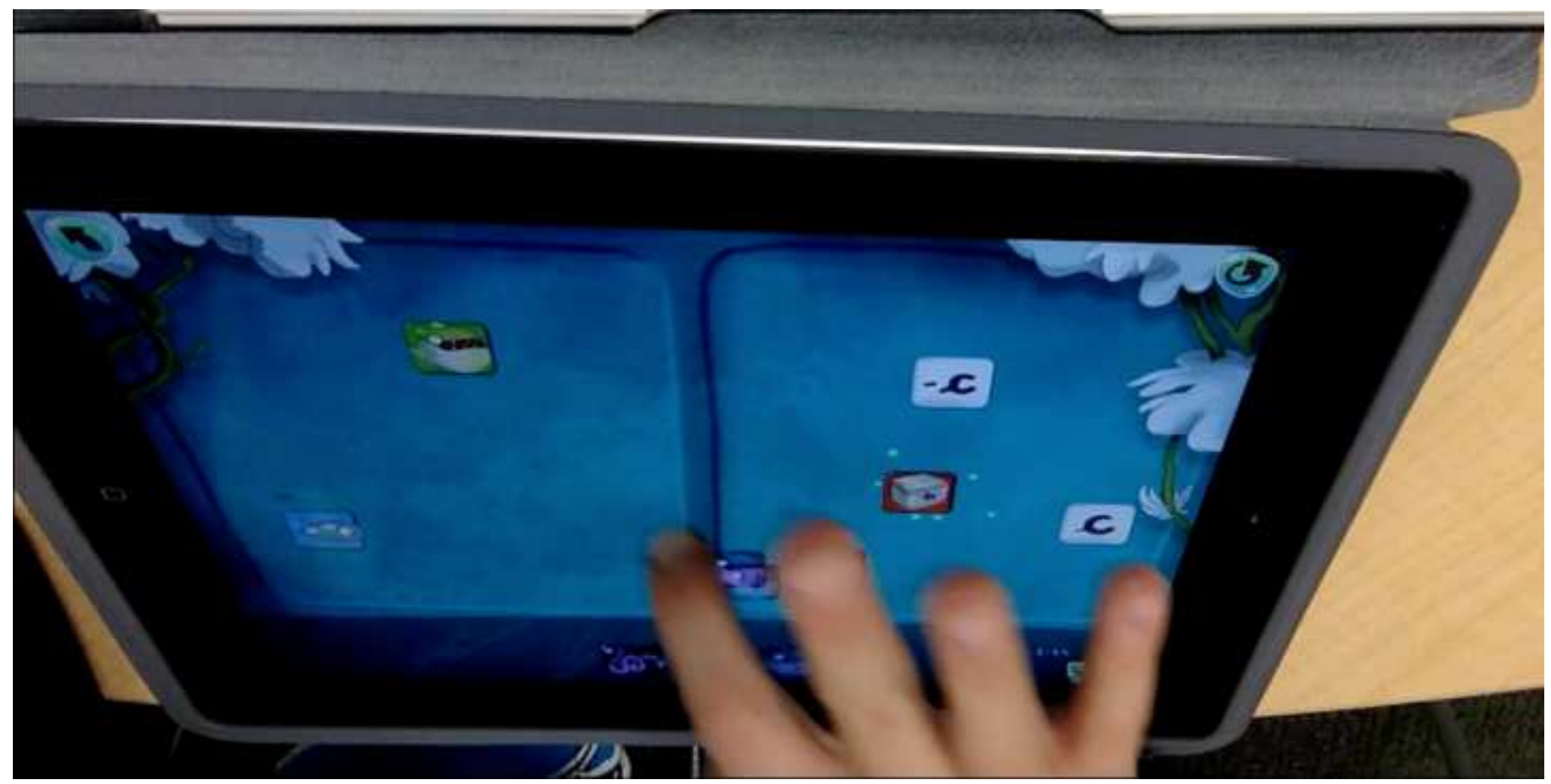

Click here to download high resolution image 
Click here to download high resolution image

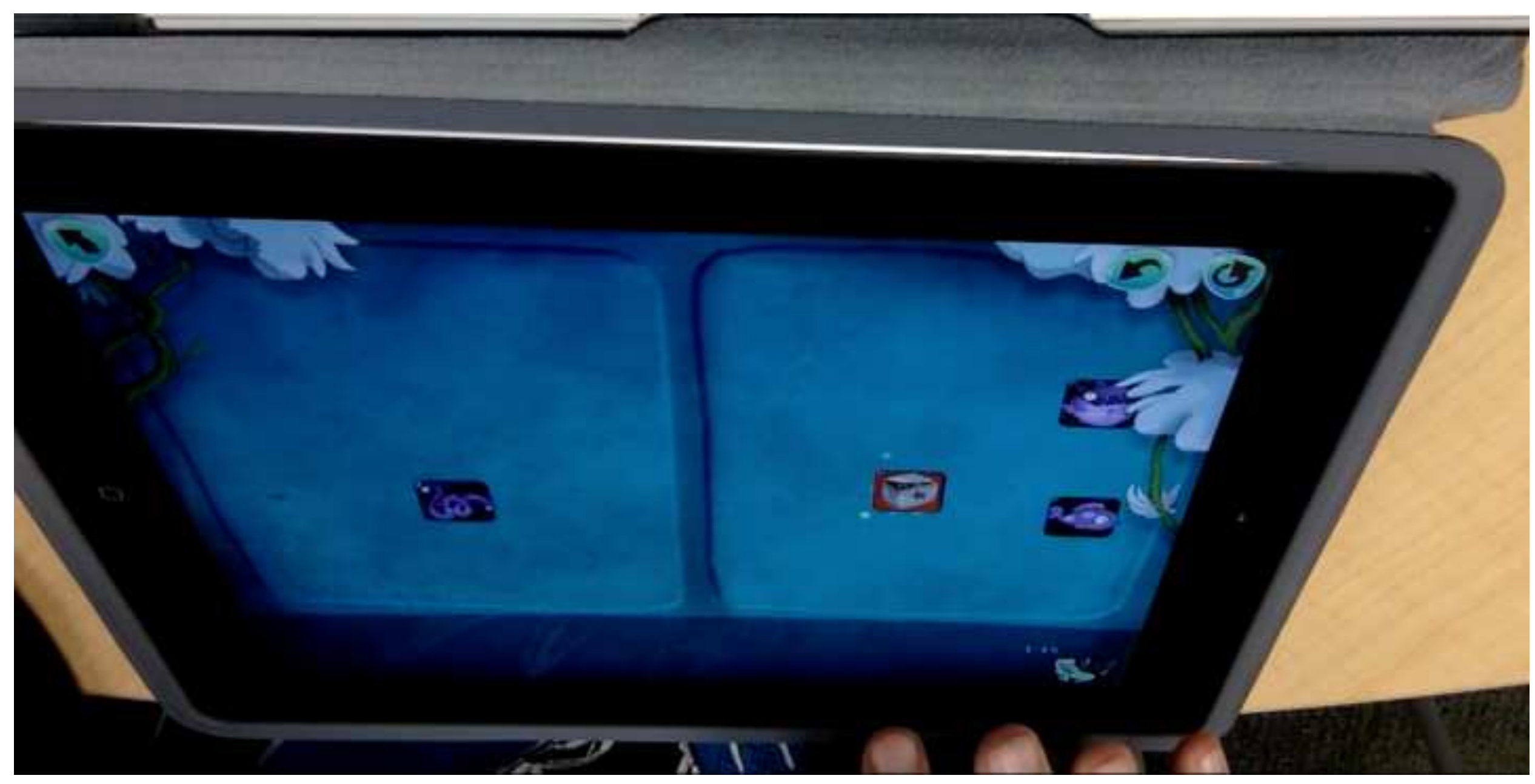

Click here to download high resolution image 
Figure(s) 8

Click here to download high resolution image

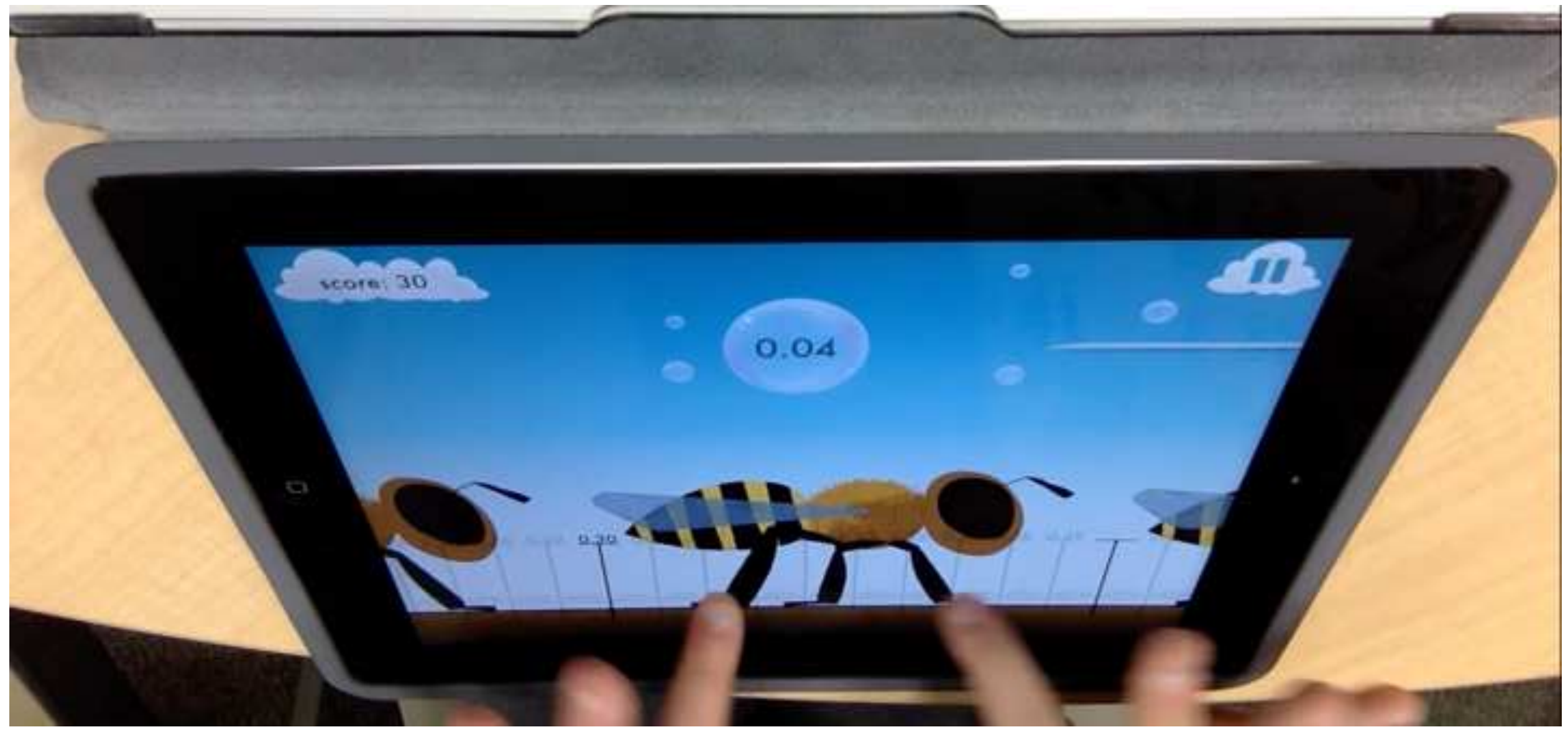




\section{(s)}

Click here to download high resolution image

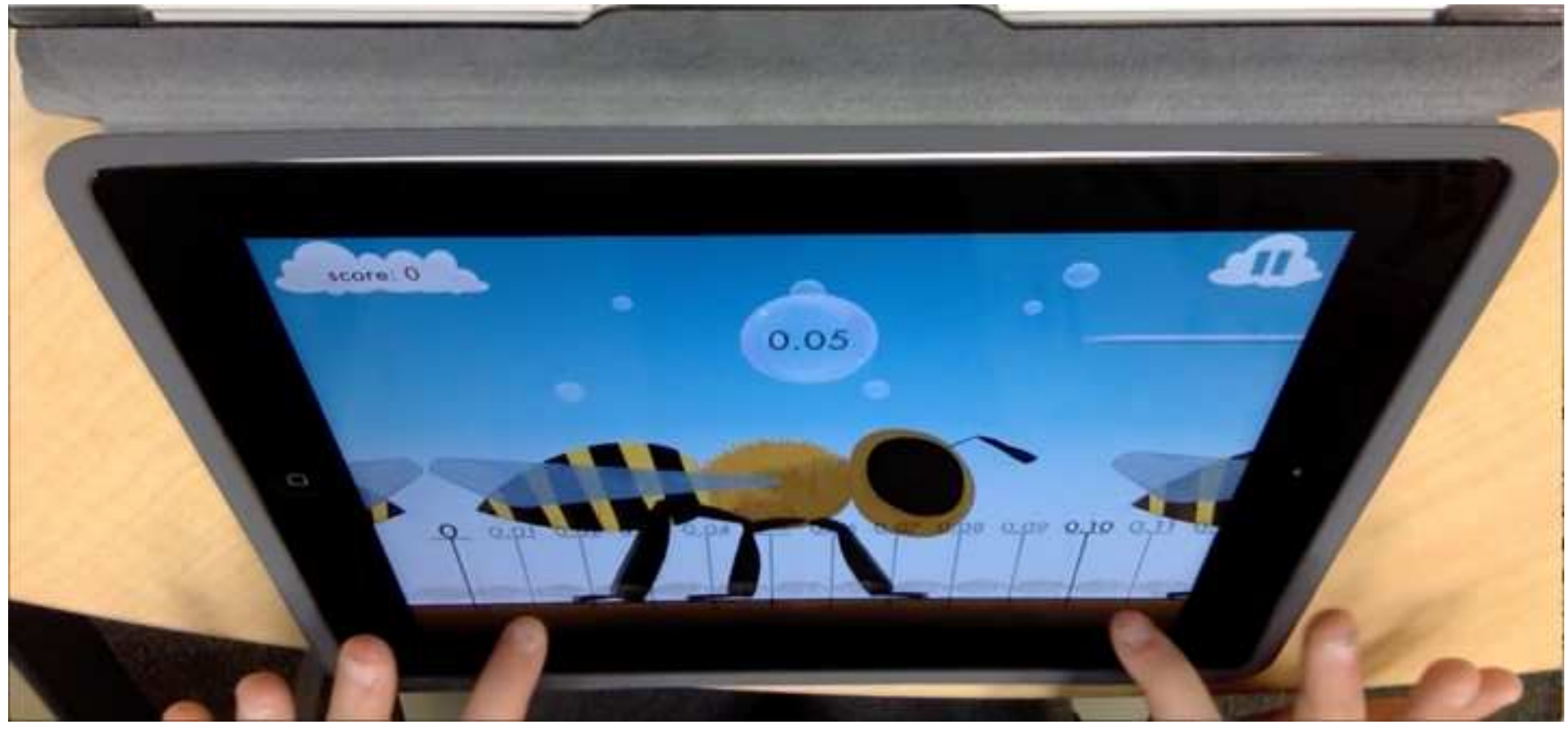


Exploring the Phenomenon of Distance in Children's Interactions with Touchscreen Digital Mathematics Games

\section{Highlights:}

- Distance is present during interactions with educational technology.

- Distance could change during these interactions.

- Mathematical and technological distance could influence each other.

- Maintaining an appropriate degree of distance may be beneficial for learning.

- An appropriate degree of distance may not always be minimal. 
Supplementary Material: Video 2
Click here to download Supplementary Material: Video2.mov

Supplementary Material: Video 2
Click here to download Supplementary Material: Video2.mov

\begin{abstract}
Click here to downloads
\end{abstract}

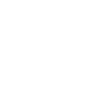

(2)

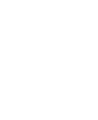

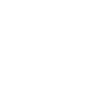

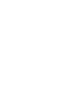

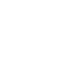

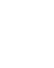

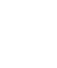

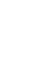
. .

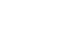
更

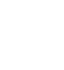

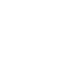
更

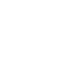

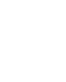

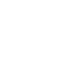
更

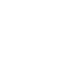
更

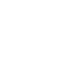

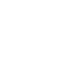

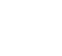


Supplementary Material: Video 3
Click here to download Supplementary Material: Video3.mov

Supplementary Material: Video 3
Click here to download Supplementary Material: Video3.mov

Supplementary Material: Video 3
Click here to download Supplementary Material: Video3.mov

(n)

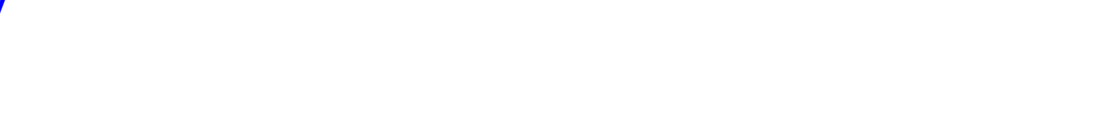

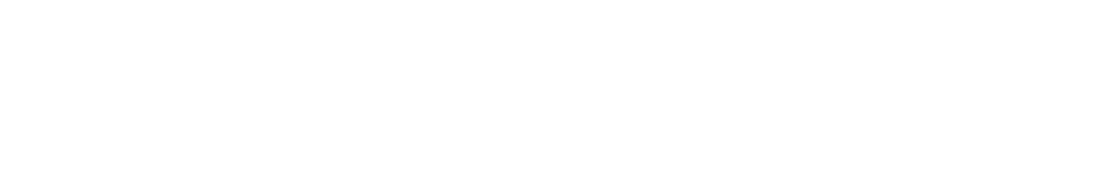

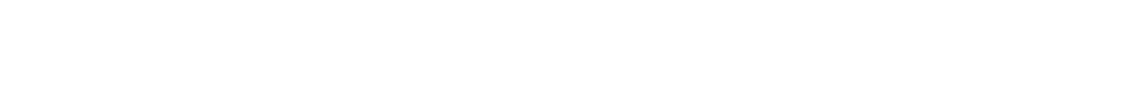

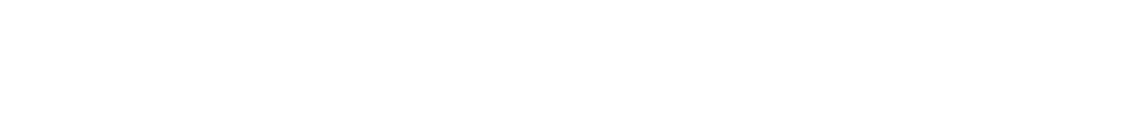
. 